\title{
Thermal Sprayed Coatings Used Against Corrosion and Corrosive Wear
}

\author{
P. Fauchais and A. Vardelle \\ SPCTS, UMR 7315, University of Limoges,
}

France

\section{Introduction}

Coatings have historically been developed to provide protection against corrosion and erosion that is to protect the material from chemical and physical interaction with its environment. Corrosion and wear problems are still of great relevance in a wide range of industrial applications and products as they result in the degradation and eventual failure of components and systems both in the processing and manufacturing industries and in the service life of many components. Various technologies can be used to deposit the appropriate surface protection that can resist under specific conditions. They are usually distinguished by coating thickness: deposition of thin films (below 10 to $20 \mu \mathrm{m}$ according to authors) and deposition of thick films. The latter, mostly produced at atmospheric pressure have a thickness over $30 \mu \mathrm{m}$, up to several millimeters and are used when the functional performance and life of component depend on the protective layer thickness. Both coating technology can also be divided into two distinct categories: "wet" and "dry " coating methods, the crucial difference being the medium in which the deposited material is processed. The former group mainly involves electroplating, electroless plating and hot-dip galvanizing while the second includes, among others methods, vapor deposition, thermal spray techniques, brazing, or weld overlays. This chapter deals with coatings deposited by thermal spraying. It is defined by Hermanek (2001) as follows , "Thermal spraying comprises a group of coating processes in which finely divided metallic or non-metallic materials are deposited in a molten or semi-molten condition to form a coating". The processes comprise: direct current (d.c.) arcs or radio frequency (r.f.) discharges-generated plasmas, plasma transferred arcs (PTA), wire arcs, flames, high velocity oxy-fuel flames (HVOF), high velocity air-fuel flames (HVAF), detonation guns (D-gun). Another spray technology has emerged recently ; it is called cold gas-dynamic spray technology, or Cold Spray (CS). It is not really a thermal spray technology as the high energy gas flow is produced by a compressed relatively cold gas $\left(\mathrm{T}<800^{\circ} \mathrm{C}\right)$ expanding in a nozzle and will not be included in this presentation.

Most processes are used at atmospheric pressure in air, except r.f. plasma spraying, necessarily operated in soft vacuum. Also, d.c. plasma spraying can be carried out in inert atmosphere or vacuum and Cold Spray is generally performed at atmospheric pressure but in a controlled atmosphere chamber to collect and recycle the spray gas (nitrogen or helium) because of the huge gas flow rates used (up to $5 \mathrm{~m}^{3} \cdot \mathrm{min}^{-1}$ ). In the following only processes 
operated in air at atmospheric pressure will be considered, except when the coating material is very expensive, such as platinum that must be sprayed in a chamber to recover the overspray.

The coating material may be in the form of powder, ceramic rod, wire or molten materials. The central part of the system is a torch converting the supplied energy (chemical energy for combustion or electrical energy for plasma- and arc-based processes), into a stream of hot gases. The coating material is heated, eventually melted, and accelerated by this hightemperature, high-velocity gas stream towards a substrate. It impacts on the substrate in the form of a stream of droplets that are generated by the melting of powders or of the tips of wires or rods in the high-energy gas stream. The droplets flatten or deform on the substrate and generate lamellae called "splats". The piling up of multiple layered splats forms the coating.

Thermal spray processes are now widely used to spray coatings against, wear and corrosion but also against heat (thermal barrier coating) and for functional purposes. The choice of the deposition process depends strongly on the expected coating properties for the application and coating deposition cost. Coating properties are determined by the coating material, the form in which it is provided, and by the set of parameters used to operate the deposition process. Thermal spray coatings are generally characterized by a lamellar structure and the real contact between the splats and the substrate or the previously deposited layers determine to a large extent the coating properties, such as thermal conductivity, Young's modulus, etc. The real contact area ranges generally between 20 to $60 \%$ of the coating surface parallel to the substrate. It increases with impact velocities of particles provided that the latter are not either too much superheated or below their melting temperature. That is why roughly the density of coatings increases from flame, wire arc, plasma, HVOF or HVAF and finally D-gun spraying and self-fluxing alloys flame sprayed and then re-fused.

Also thermal spray coatings contain some defects as pores, often globular, formed during their generation, un-molten or partially melted particles that create the worst defects, exploded particles, and cracks formed during residual stress relaxation. The cracks appear as micro-cracks within splats and macro-cracks running through layered splats especially at their interfaces and tending to initiate inter-connected porosities. Moreover, when the spraying process is operated in air, oxidation of hot or fully melted particles can occur in flight as well as that of splats and successive passes during coating formation. Thus, depending on the spray conditions and materials sprayed, the coatings are more or less porous and for certain applications must be sealed by appropriate means.

This chapter will present successively:

- the following thermal spray processes: flame, High Velocity Oxy-Fuel (HVOF), D-gun, plasma, wire arc and Plasma Transferred Arc (PTA)). The possibility to use them to manufacture coatings on site will also be mentioned. The coating structures (lamellar or granular) with their void content and the inter-connected porosities and crack networks will be linked to their corrosion resistance. The different sealing processes will also be discussed according to service temperature of coatings.

- A short introduction to the main modes of wear (abrasion, erosion and adhesion) linked to corrosion.

- $\quad$ Coatings used against atmospheric or marine corrosion (sacrificial coatings). 
- Coatings used against high-temperature corrosion: carburization, nitriding, sulfidation, molten salt, and molten glass.

- Coatings used against high-temperature oxidation.

- Coatings used against corrosive wear at different temperatures

- Examples of industrial applications to illustrate the interest of thermal sprayed coatings.

\section{Thermal spray}

In the following, we will only present the processes that are used in air at atmospheric pressure. Figure 1 shows the general concept of thermal spray, Fauchais et al (2012). The coating material can be fed in the hot gas stream as powder or wire or rod. Coatings are built by the flattening and solidification of droplets impacting onto the part to be covered. These droplets can be partially or totally melted when they are issued from powders or totally melted when they result from the atomization of melting wires or rods. The microstructure of the coating formed by the piling up of these particles depends on (i) particle impact parameters (particle temperature, molten state, velocity and size), (ii) substrate conditions (shape, roughness, surface chemistry...), (iii) the temperature control of substrate and coating before (preheating) during and after (cooling) spraying and (iv) the spray pattern.

Some general remarks can be expressed:

- Different materials require different deposit conditions,

- Specific coating properties (high density or desired porosity) may require specific particle velocity/temperature characteristics,

- The heat fluxes to the substrate depend on the coating method and for some substrate materials they have to be minimized,

- $\quad$ Substrate preheating and temperature control during spraying strongly affect coating properties and in particular residual stresses,

- And frequently a trade-off exists between coating quality and process economics.

For instance, if the plasma spray process can offer a high-temperature and high-velocity environment for the injected powders, it will bring about a strong heating of the substrate, and the powder material may undergo chemical change during the deposition due to excessive heating, e.g. WC-Co powders may decompose.

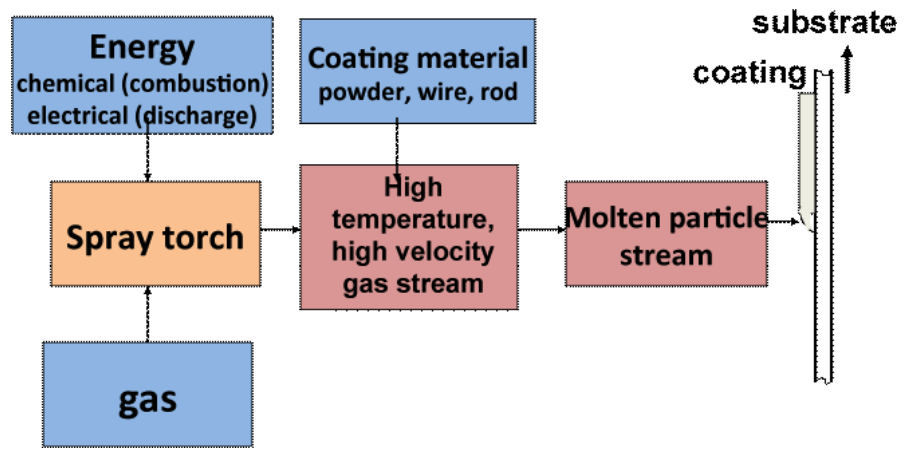

Fig. 1. Schematic of the thermal spray concept, Fauchais et al (2012) 


\subsection{Thermal spray processes}

\subsubsection{Plasma-based processes}

They comprise d.c. plasma spraying, plasma transferred arc and wire arc spraying.

d.c. plasma torches: they generate a plasma jet from a continuously flowing gas heated by conversion of electrical energy into thermal energy thanks to an electric arc striking between a thoriated cathode and a concentric anode that plays also the role of nozzle. The cathode is mostly a stick with a conical extremity for arc power levels below $60-80 \mathrm{~kW}$ and some times a button for arc power levels up to $250 \mathrm{~kW}$. The plasma torches work with $\mathrm{Ar}, \mathrm{Ar}-\mathrm{H}_{2}, \mathrm{Ar}-\mathrm{He}$, Ar-He- $\mathrm{H}_{2}, \mathrm{~N}_{2}$ and $\mathrm{N}_{2}-\mathrm{H}_{2}$ mixtures resulting in temperatures above $8000 \mathrm{~K}$ and up to $14000 \mathrm{~K}$, and velocities between 500 and $2800 \mathrm{~m} / \mathrm{s}$ at the nozzle exit. Most of applications use solid feedstock in the form of powders but recently some of them use liquid feedstock in the form of suspensions or solutions. Figure 2 from Gärtner et al (2006) illustrates mean particle temperatures and velocities achieved with the different spray processes.

Most of the plasma torches have one cathode; their electrical power level ranges from 30 to $90 \mathrm{~kW}$. For electrical powers in the range $40-50 \mathrm{~kW}$, the powder feeding rate is between 3 and $6 \mathrm{~kg} . \mathrm{h}^{-1}$ and the deposition efficiency around 50\%. With high-power plasma torches (250 $\mathrm{kW})$ powder flow rates can reach $15-20 \mathrm{~kg}^{-1} \mathrm{~h}^{-1}$. Tri-cathode torches have appeared more recently on the market with electrical power varying from 60 to $100 \mathrm{~kW}$.

Generally, plasma-sprayed coating porosities vary from 3 to $8 \%$, the oxygen content of metal or alloy coatings is between 1 and $5 \%$ and their adhesion is good (>40-50 MPa). Plasma spray processes are mainly used to spray oxide ceramics.

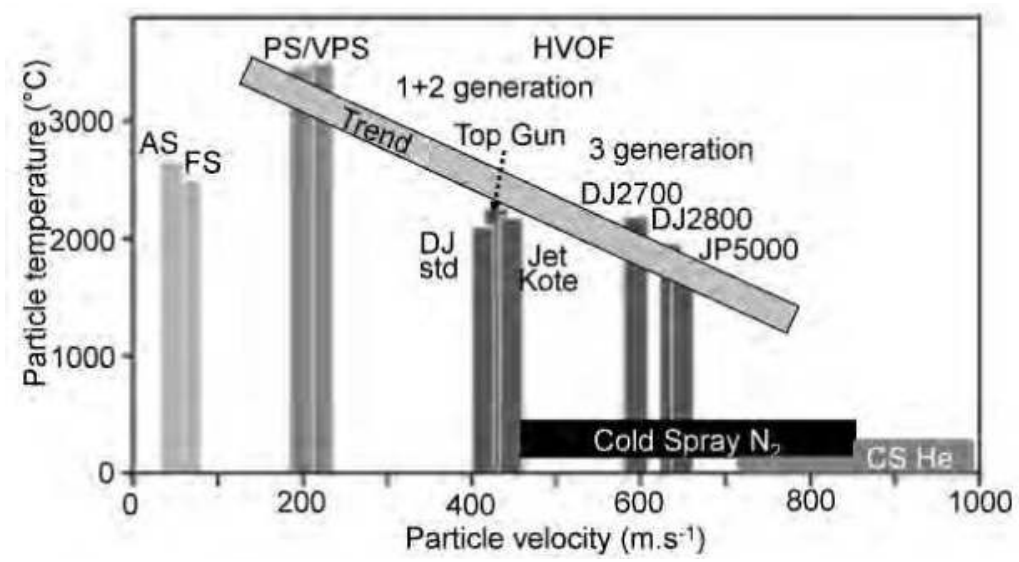

Fig. 2. Particle temperatures and velocities obtained in different thermal spray processes, as measured for high-density materials. The bar indicates the observed trend of recent developments (AS: Powder flame spraying, FS: Wire flame spraying, PS: Air plasma spraying, VPS: Vacuum plasma spraying, C.S.: Cold Spray) Gärtner et al (2006).

Wire arc spraying: instead of using solid electrodes, the arc strikes between two continuously advancing consumable conductive wires, one being the cathode and the other the anode. The melted tips of the wires are fragmented into tiny droplets, a few tens of $\mu \mathrm{m}$ in diameter, 
by the atomizing gas blown between both wires. The latter is generally compressed air but non oxidizing gas as nitrogen or argon is also sometimes used. The droplet high temperatures at impact produce metallurgical interactions or diffusion zones or both between the impinging droplets and the substrate or previously deposited layers. The wires are necessarily made of ductile material, or of a ductile envelope filled with a non-ductile or ceramic material. They are, then, called cored wires. All particles issuing from the ductile wires are fully melted at impact and their impact velocity can be as high as $120 \mathrm{~m} \cdot \mathrm{s}^{-1}$.

The maximum arc current that can vary from 200 up to 1500 A characterizes the different arc spray guns. This process has higher spray rates $\left(5\right.$ to $\left.30 \mathrm{~kg} \cdot \mathrm{h}^{-1}\right)$ than other spray processes and its deposition efficiency is about $80 \%$; it is the most economical for materials that can be processed in form of wires or cored wires. The oxide content of coatings depends strongly on the sprayed materials and the atomization gas; it is generally rather high, e.g. over $25 \%$ for Aluminum coatings. Using nitrogen instead of air as atomizing gas can reduce it, but according to the high gas flow rates (around $1 \mathrm{~m}^{3} \cdot \mathrm{mn}^{-1}$ or more), the process becomes expensive. Coating porosity is usually over $10 \%$ and its adhesion is medium in the $40-\mathrm{MPa}$ range. An advantage of this process is the little heating of the substrate while the divergence of the spray pattern is a disadvantage. As other spray processes it is noisy and dusty. Coatings can be used against abrasion and adhesion (friction) under low load but their main uses are protection against atmospheric or marine corrosion and electrical applications.

Plasma transferred arc (PTA) deposition process: PTA is different from the other thermal spray processes because the substrate serves as one electrode, usually the anode, for the arc that heats the process gases and the sprayed material. Therefore, it requires electricallyconductive substrates. The transferred arc induces a local melting of the substrate and the particles, heated in the plasma column, stick to the molten pool and are melted by the transferred arc. The process is a combination of welding and thermal spraying processes. This feature allows the attainment of excellent bonding between the substrate and the coating, and very high coating densities. The feedstock is either powders with particle sizes in the one hundred micrometer range or wires. Metals, alloys and cermets can be sprayed with this technique. The PTA guns differ in maximum arc current varying from 200 to 600A. The coatings are thicker than those manufactured by other thermal spray processes, their thickness can reach centimeters, and they are metallurgically bonded to the substrate that must be kept horizontal or close to it during spraying. Coatings do not show porosity and the process deposition efficiency is over $90 \%$. Powder flow rate can be $18 \mathrm{~kg} \cdot \mathrm{h}^{-1}$ or even more with high-power PTA devices. The coating resistance to wear is excellent as well as that to corrosion at high temperature.

\subsubsection{Combustion-based processes}

They mainly comprise flame spraying, High Velocity Oxy-fuel Flame (HVOF) or High Velocity Air-fuel Flame (HVAF) and Detonation gun (D-gun).

Flame Spray torches: they work at atmospheric pressure using mostly oxy-acetylene mixtures achieving combustion temperatures up to about 3000 K. Sprayed materials are introduced axially into the spray torch either as powders or wires, rods or cords. Flame velocities at torch exit are below $100 \mathrm{~m} . \mathrm{s}^{-1}$ and particle velocities at impact are around 50 
$\mathrm{m} . \mathrm{s}^{-1}$, as shown in Figure 2. Sprayed materials are mainly metals or polymers and many materials are commercially available, which are very easy to spray. Flame-sprayed coatings generally present a high porosity $(>10 \%)$, low adhesion $(<30 \mathrm{MPa})$ and oxide content between 6 and $12 \%$. The deposition efficiency is around $50 \%$. The particle flow rate is between 3 and $7 \mathrm{~kg} . \mathrm{h}^{1}$. Substrate and coating must be cooled during spraying.

Flame spraying can be used to deposit self-fluxing alloys; the coating process is then followed by a fusing process. Self-fluxing alloys contain $\mathrm{Si}$ and B (e.g. CrBFeSiCNi) which act as deoxidizers. Rather dense coatings can be observed when spraying self-fluxing alloys, containing $\mathrm{Si}$ and $\mathrm{B}$ with a reaction of the type:

$$
(\mathrm{FeCr})_{x} \mathrm{O}_{\mathrm{x}+\mathrm{y}}+2 \mathrm{~B}+2 \mathrm{Si} \rightarrow \mathrm{x} \mathrm{Fe}+\mathrm{x} \mathrm{Cr}+\mathrm{B}_{2} \mathrm{O}_{\mathrm{x}} \cdot \mathrm{SiO}_{\mathrm{y}}
$$

Where $\mathrm{B}_{2} \mathrm{O}_{\mathrm{x}} \cdot \mathrm{SiO}_{\mathrm{y}}$ is a borosilicate. This process requires a thermal post treatment of the coating. This "fusing" step is commonly carried out with oxy-acetylene torches very well suited to reheat the coating over the minimum of $1040^{\circ} \mathrm{C}$. During reheating oxide diffuses towards the coating surface where it is mechanically removed (turning, milling...). The process results in rather dense and hard coatings Lin and Han (1998). These self-fluxing alloys can be reinforced with hard ceramic particles such as WC, Harsha et al (2007).

Post-treated coatings have almost no porosity and exhibit an excellent adhesion thanks to diffusion at the substrate-coating interface. Self-fluxing alloys can also be deposited by plasma and HVOF spraying. These materials of brazing type are very easy to deposit. However, these coatings are limited to substrates that can tolerate the fusing temperature and possible induced distortion. So, this process can be used for steel substrates but not for Aluminum alloys! Such coatings are used against abrasion (friction, erosion) and corrosion (cold or hot).

When the coating material is in the form of wire (metallic and ductile) or cored wires (with ceramics or non-ductile materials), rod or cord (for ceramics), a compressed gas jet is used to atomize the melted tip and the noise level of the process is not negligible. However, compared to powders the variety of sprayed materials is larger. Wires of selffluxing alloys can be sprayed. Oxides are of course generated during the spray process but less than with powders and the coating oxide content is generally about 4 to $8 \%$; the deposition efficiency is also better than that achieved with powders; it is around $70 \%$. Compared to powders the material flow rate varies from 5 to $15 \mathrm{~kg} \cdot \mathrm{h}^{-1}$. With wires the coating adhesion is slightly better than that obtained with powders. The porosity is similar to that obtained with powders except for ceramic materials that are more porous but present an excellent wear resistance. Generally these coatings are used against abrasion or adhesion under low load and against atmospheric corrosion.

High Velocity Oxy-fuel Flame (HVOF) and high velocity air-fuel flame (HVAF). These processes use significantly higher upstream pressures than flame spray processes and a de Laval nozzle; they are characterized by supersonic speeds of gas flow. The combustion of a hydrocarbon molecule $\left(\mathrm{C}_{\mathrm{x}} \mathrm{H}_{\mathrm{y}}\right)$ either as gas or liquid (kerosene) is achieved with an oxidizer, either oxygen or air, in a chamber at pressures between 0.24 and $0.82 \mathrm{MPa}$ or slightly more for high-power guns. A convergent-divergent de Laval nozzle follows the combustion chamber achieving very high gas velocities (up to $2000 \mathrm{~m} / \mathrm{s}$ ). The last trend is to inject nitrogen (up to $2000 \mathrm{slm}$ ) in the combustion chamber to increase the gas velocity 
and decrease its temperature. Mostly powders are used, which are injected either axially or radially or both, depending on the gun design. Few guns have been designed to use wires or cored wires. Also, recently liquid feedstock injection (suspensions or solutions) has been developed, mainly for axial injection. The particle velocities and temperatures achieved with different guns (Top gun, Jet Kote,DJ standard, DJ 2700, DJ 2800 and JP 5000 ones) are presented in Figure 2. Substrate and coating must be cooled during spraying.

Power levels for HVOF guns working with gases is about $100-120 \mathrm{~kW}$, while they can reach $300 \mathrm{~kW}$ for guns working with liquid. Globally this process, working mainly with metals, alloys and cermets (one of the most successful applications) has deposition efficiencies of about $70 \%$ for powder flow rates up to $7.2 \mathrm{~kg} . \mathrm{h}^{-1}$ for gas-fuel guns and up to $12 \mathrm{~kg} . \mathrm{h}^{-1}$ for liquid-fuel guns. Resulting coating porosities are a few \%, with a good adhesion to substrate (roughly 60 to $80 \mathrm{MPa}$ ) and low oxygen content (between 0.5 and a few \%). The process is rather noisy, dusty with large quantities of explosive gases. As for detonation-gun (see below), the main applications of coatings are protection against abrasion and adhesion (friction) under low load as well as protection against corrosion.

Detonation gun (D-gun). The detonation is mainly generated in acetylene- or hydrogenoxygen mixtures (with some nitrogen to modify the detonation parameters) contained in a tube closed at one of its ends. The shock wave created by the combustion in the highly compressed explosive medium results in a high pressure wave (about $2 \mathrm{MPa}$ ) pushing particles heated by the combustion gases. Gas velocities of more than $2000 \mathrm{~m} / \mathrm{s}$ are achieved. Contrary to the flame and HVOF devices where combustible gases and powders are continuously fed within the gun, combustible gases and powder are fed in cycles repeated at a frequency of 3 to $100 \mathrm{~Hz}$.

The resulting deposits are dense and tightly bonded to the substrate. The process is the nosiest of all the thermal spray processes (more than $150 \mathrm{dBA}$ ). Coating porosity is low (below $1 \%$ ) and its oxygen content is between $0.1-0.5 \%$. The deposition efficiency is about $90 \%$, for powder flow rates of 1 to $2 \mathrm{~kg} \cdot \mathrm{h}^{-1}$. The sprayed materials are mainly powders of metals, alloys and cermets; some oxides can be sprayed but with particle sizes in the $20-\mu \mathrm{m}$ range or below. Substrate and coating must be cooled during spraying. The main applications are coatings against abrasion and adhesion (friction) under low load as well as coatings against corrosion.

On-site spraying: Many applications, especially those on big parts, e.g. a bridge, require that spraying is performed on site. This is feasible with wire arc, flame and in certain cases HVOF.

\subsection{Coating formation}

Compared to many other material processes, coatings produced by thermal spraying generally contain many defects. (i) The real contact area between the splat and the substrate or the previously deposited layers determines the coating properties. Inter-lamellar pores exist between layered splats, or first splats and substrate; their thickness is between a few hundredths to a few tenths of micrometers. The real contact between splats increases from about 20 to $60 \%$ with particle impact velocities, provided that particles are not either too much superheated or below their melting temperature. (ii) Splashing of the melted particles 
during flattening upon impact can significantly affect the coating properties Gawne (1995). Splats deposited on splashed material exhibit lower adhesion and this effect is more significant when spraying metals because the splashed material is oxidized rather fast due to the small droplet sizes. (iii) Substrate geometry may affect the flow of impacting and splashing particles Racek (2010). (iv) Pores, often called globular, are formed during coating generation because of shadowing effect, narrow holes in valleys between splats not completely filled, un-molten or partially melted particles and exploded particles. These globular pores are distributed more or less homogeneously through the coating and their potential to deteriorate coating properties is proportional to their size, Ctibor et al (2006). Therefore, to reduce the coating porosity, the incorporation in the coating of large unmelted particles, which are sufficiently heated to stick on the substrate, or of partially melted particles, must be avoided. This can be done by choosing carefully the particle size distribution and optimizing the particle injection. However, sometimes a compromise has to be found between having most particles fully melted but with rather high oxide content, and more un-melted particles with lower oxide content. (v) Coatings also contain cracks formed during residual stress relaxation and that often contribute to the open porosity of coatings. The micro-cracks within splats result from quenching stress relaxation and are observed in ceramic materials. The macro-cracks are often due to the relaxation of an expansion mismatch stress; they run through layered splats especially at their interfaces and, so, tend to initiate inter-connected porosities. Other stress relaxations can occur but they can be avoided by optimizing spray or service conditions. (vi) At last, another source of defects is the particle impact angle that reduces the normal impact velocity, resulting in elongated splats. Spraying with an angle above a certain value, depending on particle and substrate materials, will promote splashing even on substrates preheated above the so called "transition temperature". Above this temperature, the splats exhibit a regular disk shape on a smooth substrate while below they have an irregular shape. Typically, depending on the spray process used and the material sprayed total porosity varies between 0.5 and $15 \%$. It does not mean necessarily that porosities are inter-connected, but it can happen.

Figure 3 illustrates schematically the structure of a thermal-sprayed coating. Figure $4 \mathrm{a}$ presents the cross section of a stainless steel coating (304L) deposited by air plasma spraying on a low carbon (1040) steel substrate and Figure $4 \mathrm{~b}$ that of an yttria partially stabilized zirconia (Y-PSZ). Figure $4 \mathrm{a}$ and Figure $4 \mathrm{~b}$ show all the coating characteristics presented in the schematic cross section in Figure 3, except that the Y-PSZ coating (Figure 4b) does not present, of course, oxidation and its lamellar structure is more pronounced.

It should be noticed that microstructural homogeneity, process reproducibility and precise dimensional tolerances are indispensable requirements in manufacturing of coatings. Net shape and high precision dimensional deposition of coatings are essential for cost efficiency, especially in the case of hard coatings that require machining and finishing. The movement and velocity of the robot-guided torch has a crucial importance, especially for net-shaped coatings on complex 3D geometries, on the final properties of coating: thickness, roughness, adhesion, porosity, thermal stress distribution, etc. It is thus mandatory to develop software toolkits for the off-line generation, simulation and implementation of movement (position and orientation) of the spray torches Candel and Gadow (2006). 


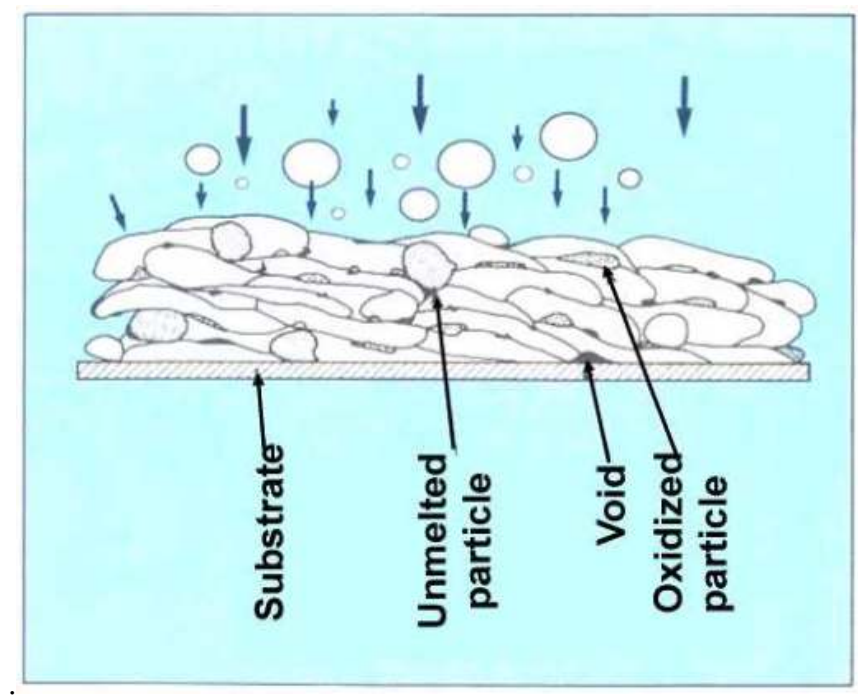

Fig. 3. Schematic cross section of a thermally-sprayed coating

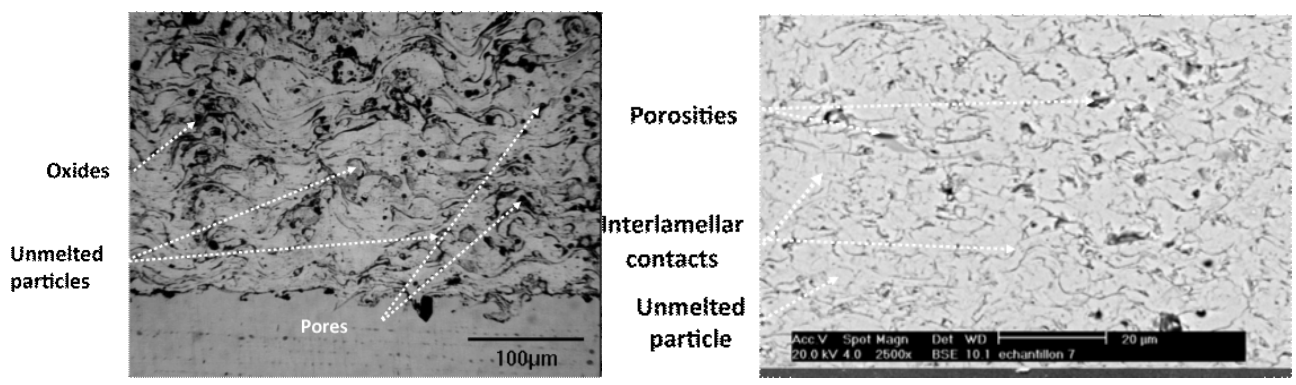

Fig. 4. (a) Stainless steel coating (304L) deposited by air plasma spraying on a low carbon (1040) steel substrate, (b) Y-PSZ ( $8 \mathrm{wt} \%$ ) coating deposited by air plasma spraying on a super alloy

\subsection{Coating sealing or post-treatment}

When thermally-sprayed coatings are porous, especially with connected porosities, they are not very suitable for corrosion protection. This situation can be drastically improved by curing their inter-connected porosities through sealing or by post-treatments that are generally thermal. The sealing or post-treatment process depends on the coating material and its service conditions and, also, on the cost that the customer can accept. The advantages, Davis (2004), are the following: prevention of the penetration within coating of the corrosive substance (liquids or gases) and the attack of the coating/substrate interface, limitation of the lodging of wear debris in the coating, enhancement of inter-splat cohesion, granting of special surface properties such as non-stick surfaces, extending the life of 
aluminum or zinc coatings on steel to prevent corrosion. However it must be kept in mind that such post-treatments increase more or less the cost of the coating.

Knuuttila et al (1999) gave a description of the sealing process presenting various sealant types and impregnation methods, as well as the factors influencing impregnation. Impregnation methods can be divided into four categories: atmospheric pressure impregnation, low-pressure impregnation, overpressure impregnation, and a combination of the previous methods. The choice depends on the size of the coated component, the required penetration depth, and the sealant. The choice of the latter also depends on the coating material and the application. The often-used organic sealants are based on epoxies, phenolics, furans, polymethacrylates, silicones, polyesters, polyurethanes, and polyvinylesters. Waxes can be used as well. The choice depends upon the service temperature. For example wax can be used only in cold conditions, phenolic resins up to $150-260^{\circ} \mathrm{C}$ and methacrylate up to $150^{\circ} \mathrm{C}$. Inorganic sealants are mostly used for hightemperature applications. Besides aluminum phosphates, sodium and ethyl silicates, various sol-gel type solutions and chromic acid have been used for sealing purposes. For example phosphate acts as refractory glue that forms solid bridges over pores and cracks; it has also a beneficial effect in transforming the residual stresses of the coating into compressive stresses. Sol-gel processes refer to the formation of a stable sol, the hydrolyzing of the sol to a gel, and the calcination of the gel at elevated temperature to oxide. The sol includes a variety of metal alkoxides, nitrates, or hydroxides. Molten metals are also used for sealing and strengthening purposes. The metal-coating wetting is, then, a key issue. For example zirconia is completely wetted by liquid pure manganese. Electroplating or glazing (enamel deposition) can also be used.

Other solutions can be used to improve coating density and two examples are presented below.

- Coating properties can be improved by annealing. By definition annealing corresponds to a heat treatment that alters the microstructure of a material causing change in properties such as strength, hardness, ductility, etc. For thermally-sprayed coatings, annealing or heat-treating is performed Davis (2004) at high temperatures, but well below the coating melting temperature, $\mathrm{T}_{\mathrm{m}}$. It takes place at atmospheric pressure in air or more generally in a controlled atmosphere or under vacuum and may induce changes in coating microstructure and thermo-mechanical properties. Annealing may result in the formation of amorphous phase, the relaxation of residual stress (temperature must be over that of recovery $\approx 0.4 \times \mathrm{T}_{\mathrm{m}}$ ), diffusion between substrate and coating improving the bond strength, the coating densification by increasing inter-splat cohesion. It also may lead to recrystallization and grain growth occurring through sintering, reduction of coating oxide content when heated in hydrogen atmosphere or complete oxidation when heated in oxygen atmosphere, carbide precipitation from solid solutions with cobalt, thus enhancing the coating toughness.

- Another means to promote diffusion at the substrate and coating interface and to collapse the internal pores is to use some austempering process that consists of quenching the part directly into a liquid salt bath. For example Lenling et al (1991) used this process for plasma-sprayed composite coatings consisting of WC-Co and Ni-base, about $250-\mu \mathrm{m}$ thick deposited onto AISI 5150 steel substrates. The samples were 
immersed in a $870^{\circ} \mathrm{C}$ neutral salt for $30 \mathrm{~min}$, quenched in a neutral salt bath at $315^{\circ} \mathrm{C}$ for $30 \mathrm{~min}$ and finally cooled and rinsed with room temperature water. After this treatment, the samples showed an increase in the percentage of WC phase and less desirable carbide phases formed during plasma spraying were eliminated. The bonding to substrate was improved, the coating hardness increased and residual compressive stresses appeared.

- The advantage of laser heat treating and glazing is that the amount of thermal energy applied to the surface and the location on the surface to be treated are well controlled Davis (2004). For treated surfaces, the intensity of the hemispherical reflection coefficient, $\mathrm{R}$ of the coating, must be considered, the energy or power absorbed by the surface being proportional to (1-R). Using a wide range of energy densities makes it possible to get accurate temperature profiles at precise locations at different depths in the coating. The treatment enables the heat treating or melting of the surface (laser glazing). It must be kept in mind that coatings with low thermal conductivities (below $30-40 \mathrm{~W} . \mathrm{m}^{-1} \cdot \mathrm{K}^{-1}$ ) may exhibit high temperature gradients that induce important stresses. The latter are generally relaxed by macro-cracks orthogonal to the coating.

\section{Coatings and corrosion}

The different types of corrosive attack, especially for coatings can be classified as (i) general corrosion, corresponding to about $30 \%$ of failure, where the average rate of corrosion on the surface is uniform and as (ii) localized corrosion, corresponding to about $70 \%$ of failures. The latter comprises: (i) galvanic corrosion occurring when two dissimilar metals are in contact with each other in a conductive solution (electrolyte), the more anodic metal being corroded, while the more cathodic one is unaffected. The electrolyte plays a key role, as well as the relative surface contact area; the smaller the anodic to cathodic area ratio is, the more severe is the anodic metal corrosion. For example the protectection of low-carbon iron part from atmospheric corrosion by a coating may use either an anodic coating (nickel) or cathodic one (aluminum or zinc). In the first case no discontinuity in the coating can be tolerated, while it has no importance with cathodic coating, as illustrated in Figure 5, (ii) inter-granular corrosion, occurring when a chemical element is depleted during the coating or bulk material manufacturing, e.g. during heat treatment, (iii) pitting, which is a localized corrosion characterized by depression or pit formation on the surface. It occurs for example when stainless steel is corroded by chloride-containing solutions, (iv) transgranular corrosion is mainly due to high static tensile stress in the presence of a corrosive environment. It can be intergranular but also transgranular when cracking occurs. The coating material and its microstructure play an important role in this type of corrosion.

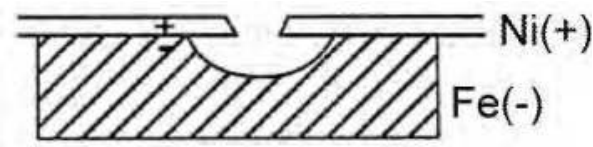

a. Anodic protection

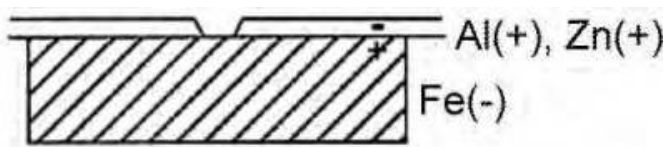

b. Cathodic protection

Fig. 5. Examples of protective coatings: a). Anodic (no discontinuity possible in the coating), b). Cathodic (discontinuity possible in the coating, resulting in no corrosion of iron). 
Thus coatings can be used against corrosion:(i) As sacrificial coatings (cathodic behavior relatively to ions, for example $\mathrm{Zn}$ or $\mathrm{Al}$ on steel): the thicker they will be the longer will be the protection (typical thickness varies between 50 and $500 \mu \mathrm{m}$, the most frequent one being around $230 \mu \mathrm{m})$,

(ii) As dense as possible (even sealed) if they have an anodic behavior and used against either atmospheric or marine corrosion, and high temperature corrosion: oxidation, carburization, nitriding, sulfidation, molten salt, molten glass...

Corrosive wear occurs when the effects of corrosion and wear are combined, resulting in a more rapid degradation of the material surface. A surface that is corroded or oxidized may be mechanically weakened and more likely wear out at an increased rate. Furthermore, corrosion products, including oxide particles, which are dislodged from the material surface can subsequently act as abrasive particles. Stress corrosion failure results from the combined effects of stress and corrosion. At high temperatures reactions with oxygen, carbon, nitrogen, sulfur or flux result in the formation of oxidized, carburized, nitrided, sulfidized, or slag layer on the surface. Temperature and time are, then, the key factors controlling the rate and severity of high temperature corrosive attack Chattopadhyay (2001).

\section{Applications of thermal coatings against corrosion}

\subsection{Land-based and marine applications}

\subsubsection{Sacrificial coatings}

The corrosion protection of large steel structures such as bridges, pipelines, oil tanks, towers, radio and television masts, overhead walkways and large manufacturing facilities in the metallurgical, chemical, energy, and other industries is a key issue. The protection of structures exposed to moist atmospheres and seawater such as ships, offshore platforms, seaports, is even more difficult Evdokimenko (2001). In most cases the surface to be protected is thousands and even tens of thousands of square meters, requiring that coating costs are competitive with those of traditional painting methods. The coating rate must be at least 10 $\mathrm{m}^{2} / \mathrm{h}$ and coating must be, if possible, deposited in one unique pass; the equipment must be mobile and autonomous for operation in field conditions and can work under manual control, automation being generally difficult for large scale operations, and at last the spray gun can be up to $30 \mathrm{~m}$ away from other elements of the equipment Evdokimenko (2001). Flame and wire-arc spraying meet such requirements. These equipments are widely used in industry because the investment is rather low and also coating adherence is generally good (over $20 \mathrm{MPa}$ ), with almost no heating of the substrate. However coatings obtained by these methods are relatively porous (up to $20 \%$ ). This porosity can be reduced by shot peening just after spraying. For example the initial porosities of 4 to $14 \%$ (depending on spray conditions) of aluminum coatings deposited by wire- arc was reduced to 0.16 to $0.83 \%$ after being shot peened with SiC glass beads of 0.21 to $0.3 \mathrm{~mm}$ in diameter Pacheo da Silva (1991).

Therefore, the main use of thermal sprayed coatings is as sacrificial coating with typical thicknesses between 50 and $500 \mu \mathrm{m}$. Referring to section 3, such coatings must have a cathodic behavior relatively to the ions of the metal to be protected, in almost all cases steels. As illustrated in Figure 5b, the cathodic protection can be porous without any corrosion of the underneath metal. Metals used are then zinc, aluminum and zinc-aluminum. Zinc 
performs better than aluminum in alkaline conditions, while aluminum is better in acidic conditions. If resistance to wear must be improved, aluminum coatings can be sprayed with alumina particles, e.g. by using cored-wires. For the protection of steel reinforcement in concrete, zinc is generally used, but titanium has also been used. In that case the coating is applied directly on the concrete substrate, Davis (2004). However with wire-arc spraying the atomization of the wire tips must be performed with nitrogen to limit as much as possible the formation of $\mathrm{\gamma} \mathrm{TiO}_{2}$ Holcomb (1997). Aluminum must be avoided where thermite sparkling may occur. That is due to the reaction of rusted steel and aluminum smears when this combustible mix is ignited by an impact Davis (2004). Thus they must be avoided whenever there is a thermite-sparking hazard. Another interest of such coatings is their antifouling properties. Marine bio fouling is the undesirable accumulation of marine organisms on artificial surfaces that are immersed in the sea. When marine bio fouling occurs on ship hulls, it leads to an increase in the weight of the ship and friction to sail. Murakami and Shimada (2009) have studied the corrosion and marine fouling behaviors of various flame sprayed coatings. They used the following powders as coating material: aluminum-copper alloy powders, aluminum-copper blend powders, aluminum-zinc blend powders and a zinc powder. After immersion in the sea, the aluminum-copper coatings showed poor anticorrosion and anti-fouling properties. The aluminum-zinc coating with high zinc content and the zinc coating possessed the best anti-corrosion and anti-fouling properties. For example sluice gates and canal lock gates of the St. Denis Canal in France that have been zinc coated in the early 1930s have remained in perfect condition with virtually no maintenance for decades. According to Davis (2004) the lifetime of a 255- $\mu \mathrm{m}$ thick zinc or zinc aluminum coating is about 25 years and it can be extended by 15 years by sealing it with vinyl paint. Besides painting, impregnation with special compositions (epoxy resin, silicon resin...) is also intensively used as sealer. As soon as sealing is considered, the porosity of these coatings becomes an advantage for the adhesion of the sealer. Figure 6 represents an iron bridge arc-sprayed with zinc and then painted.

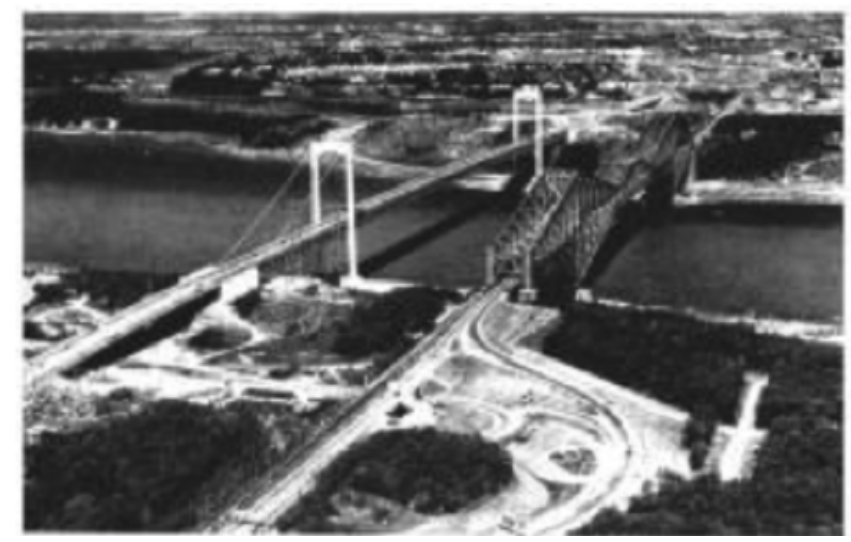

Fig. 6. Iron bridge arc-sprayed with zinc and then painted Ducos (2006).

Sealers can also present anti-fouling properties. Chun-long et al (2009) have arc-sprayed aluminum on steel panels and then sealed coatings with nano-composite epoxies especially developed for this application. Test panels were tested during three years in the East China 
Sea. They were disposed in the marine atmosphere zone, seawater splash zone, tidal zone and full-immersion zone. The tests included marine atmospheric outdoor exposure test, seawater exposure corrosion test and coating adhesion test. It was found that the appearance of coated panels was as fine as original but with a little sea species adhering to panels when they were immersed in tidal zone and full-immersion zone. Basically no change in the morphology, bond strength and no visible coating crack, blister, rust and break off was observed.

\subsubsection{Non-sacrificial coatings}

Austenitic stainless steels, aluminum bronze, nickel-base alloys, super-alloys MCrAlY where $\mathrm{M}$ is $\mathrm{Ni}$, Co or $\mathrm{Ni}-\mathrm{Co}$, cermets (metal matrix re-enforced with $\mathrm{WC}, \mathrm{Cr}_{2} \mathrm{C}_{3}$, and matrices containing chromium or nickel or both are used against corrosion, often when it is associated with wear. However such coatings, presenting no galvanic protection, will never protect the substrate if connected porosities and oxide networks exist, which is the case in most of thermal-sprayed coatings. Therefore, the substrate protection requires using a protective bond coat or producing dense coatings, or sealing them. The latter operation is not always possible if the service temperature is over a few hundreds of Celsius degrees. A few examples will be presented below. According to Moskowitz (1993), the use of vacuum chambers or post-treatments can eliminate most defects, but these methods are costly and impractical on a large scale. Thus, he proposed using modified HVOF process with unique inert gas shrouding to achieve highly-dense, low-oxide coatings of metallic alloys. Coatings of corrosion-resistant alloys for severe petroleum industry corrosion applications, such as type 316L stainless steel and Hastelloy C-276, were shown to act as true corrosion barriers. The oxide content also plays a role. For example 316L stainless steel coatings formed by HVAF and HVOF where applied on carbon steel panels and their resistance to salt spray was tested as sprayed or sealed Zeng et al (2008). When coatings were sealed, corrosion was less on the HVAF coatings than that on the sealed HVOF coating, and almost no corrosion was observed on the sealed coating sprayed with powder of the largest particles (highest porosity) after even $500 \mathrm{~h}$ of salt spray testing. While the amount of through pores dominates the corrosion resistance of as-sprayed coatings, the degree of oxidation of the coatings (much less with HVAF) determines the corrosion resistance when sealing is applied.

For applications in oil and gas industry on parts subjected to severe wear, cermets are used, with however some problems for offshore installations. According to Meng (2010) the choice between the wide varieties of tungsten carbides with different alloying binders is not simple. The corrosion resistance of coatings can be improved by the proper choice of binder. For example, Souza and Neville (2003) have shown that WC-CrNi exhibits passive behavior, as stainless steel, and would be compatible for use as a coating/substrate system when exposed to seawater, which is not the case for WC-CrC-CoCr. As previously mentioned the coating porosity and its oxide content must be as low as possible. It is why HVOF guns are largely used as they result in higher impact velocities (and so low coating porosity), and lower particle temperatures (and so less particle oxidation) as shown by Ishikawa et al (2005). They used a commercial HVOF gun with a gas shroud attachment (GS-HVOF) to prepare WC-CrC-Ni coatings. Results of corrosion test indicate that through porosity was eliminated 
at velocities above $770 \mathrm{~m} / \mathrm{s}$ with a lower degree of WC Degradation, wear resistance and hardness of coatings prepared by GS-HVOF were superior to those prepared by the conventional HVOF. Fedrizzi et al (2007) showed that $\mathrm{Cr}_{3} \mathrm{C}_{2}-\mathrm{NiCr}$ coatings, in sodium chloride solution under sliding wear, presented good barrier properties and substrate corrosion was never observed. Moreover, when chromium was added to the metal matrix of WC-Co based systems, tribo-corrosion behavior was enhanced and the lower tribocorrosion rates were measured. Plasma sprayed $\mathrm{Cr}_{2} \mathrm{O}_{3}-8$ wt. $\% \mathrm{TiO}_{2}$ coatings were used on hydraulic cylinder piston rods and rolls but the substrate was rapidly corroded by the diffusion of the corrosive solution through pores: the bond coating was destroyed by the aggressive solution and ceramic coating flakes dropped off. Zhang et al (2011) have sealed coatings with epoxy and silicone resins. The sealing treatment improved significantly the corrosion resistance of coatings by blocking the open pores and cracks of the coating. Sealed by silicone resin, the coating gained remarkable anti-corrosion properties and after 1200-h salt spray test, no rust was observed on the silicone resin sealed coating.

The selection of bulk materials and coatings of valve components is an important factor for the economic success of oil and gas production activities in the petrochemical field. Particle erosion and surface wear are associated to corrosion by hydrogen sulphide during oil and gas flow. For such applications, Scrivani et al (2001) have characterized the following HVOF coatings : NiAl and composite material WC/intermetallic compounds containing $\mathrm{Ni}, \mathrm{Cr}$, Co and Mo. WC-CoCr carbide coatings showed high erosion resistance due to their elevated micro hardness. Also WC/Mo compound, because of its carbide content, showed fairly good behavior in an erosive environment while WC/Mo compound showed an higher erosion resistance than Inconel 625 and NiAl.

Al alloys find increasingly large industrial use, in accordance to their high strength-todensity ratio and elastic modulus-to-density ratio. These alloys depending on their composition, besides their poor tribological behavior, can be prone to localized corrosion (e.g., pitting) in some particularly aggressive environments (e.g. seacoast atmosphere). To prevent these drawbacks, protective coatings or surface treatments are often employed. Barletta et al (2010) have studied the resistance of WC-CoCr coatings HVOF-sprayed onto AA6082T6 substrates. Coatings with thickness ranging between 50 and $150 \mu \mathrm{m}$ were produced by stepwise increase of the number of torch scans. An increase in coating thickness came along with an increase in coating density because of peening effect and modifications of the splat formation mechanism. Thanks to coating densification, the hardness, wear and impact resistance, and corrosion protectiveness of the layers increased with the number of torch scans. The largest improvement occurred from 2 to 3 torch scans. When compared to anodized films these coatings had superior wear and impact resistance but offered less corrosion protection.

\subsection{Low or moderate temperature coatings}

\subsubsection{Polymers}

Thermal spraying of polymers (see for example Petricova et al (2002), Leivo et al (2004), Zhang T. et al (1997), Chen et al (1999), Zhang C. et al (2009) and Henne and Schitter (1999)) is one-coat process that acts as both the primer and the sealer, with no additional cure process. Polymer thermal spraying is ideally suited for large structures that otherwise could not be dipped in 
a polymer suspension. Moreover it seems that functionalized polyethylene polymers such as ethylene methacrylic acid copolymer (EMAA) and ethylene acrylic acid (EAA) can be applied in high humidity. Of course the use of polymer coatings depends strongly on their service conditions. Especially it must be kept in mind that melting temperatures vary from $40-60{ }^{\circ} \mathrm{C}$ for ethylene methacrylic acid copolymer (EMAA) to $300^{\circ} \mathrm{C}$ for polyimide.

Compared to thermal spraying of conventional materials (metals, cermets and ceramics) the first necessity with polymers is to adapt the spray conditions and the polymer particle sizes to melt them partially with no overheating. It requires first to eliminate the smallest particles that are easily over heated, as well as the bigger ones that are not enough melted. Then, the residence time of particles must be adapted in order to avoid their over heating. However, polymer spraying has a certain number of limitations, particularly on coating quality, e.g. high porosity, low interfacial adherence. For that reason a thermal post-processing step is often necessary. For example Zhang et al (2009) and Soveja et al (2010) have studied the effect of laser (Nd:YAG, $\mathrm{CO}_{2}$ or diode lasers) heat treatment on the morphological structure (compactness) and mechanical properties (adherence and tribological properties) of flamesprayed PEEK and PTFE coatings. Whatever the laser wavelengths used, the laser treatment resulted in an improvement of the compactness and adherence to the substrate of both polymer coating.

Polymers may be deposited onto metals, ceramics, cermets, and composites substrates ... As they present a high chemical resistance, a rather high impact and abrasion resistance at low temperatures, they are used in many industries, especially in food industry. Figure 7 represents flame-sprayed polyamide coating, 3-mm thick, deposited on a cylinder used in food industry.

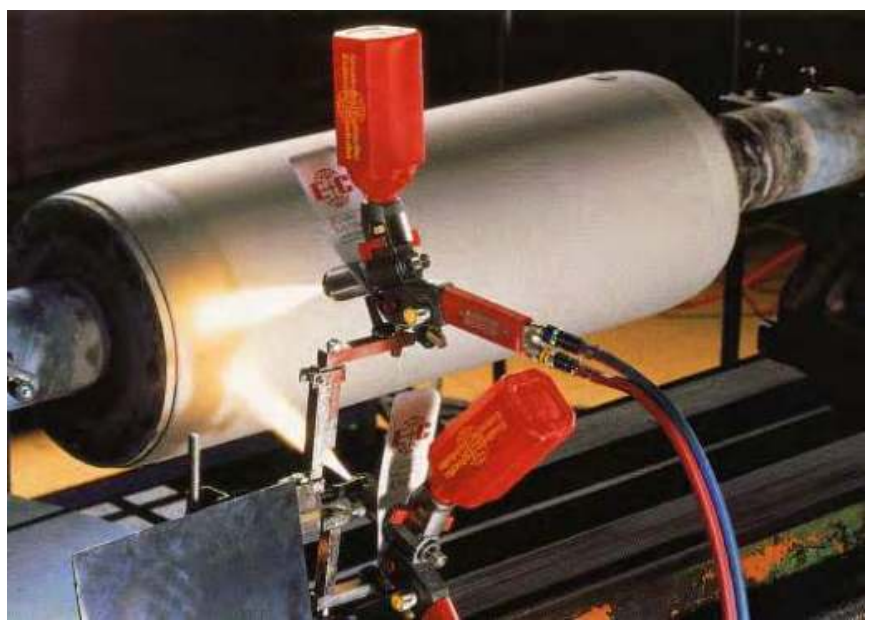

Fig. 7. Flame-coating of a cylinder used in food industry: 3-mm thick polyamide coating Ducos (2006).

In food industry, polymer coatings replace paints on the wall because they have a much better resistance to the chemical products used for cleaning (about one week for paint against about four for the polymer coating). They are even used on the floors where 
polymer coatings doped with alumina particles provide an excellent anti-slip lining, the alumina particles rippling out when people walk on it.

In petroleum industry, the protection of external steel structures, pipes, tanks... is achieved with $\mathrm{Al}, \mathrm{Zn}$ or $\mathrm{Zn}-\mathrm{Al}$ wire arc sprayed Davis (2004), as well as polymers sprayed by using flame, HVOF or plasma according to the polymer melting temperature Petrovica et al (2002).

\subsubsection{Pulp and paper}

Machine producing paper and cardboard comprise many parts that can have large dimensions (e.g. rolls over one meter in diameter and ten meters in length) and are subjected to high wear and corrosion problems. Coatings are used for several types of rolls and cylinders, including for instance, center press rolls, dryer cylinders, calender rolls, traction rolls, and Yankee cylinders Vuoristo and Nylen, (2007). Coating materials used are iron- and nickel-base alloys, nickel-chromium self-fluxing alloy, carbides, oxide ceramics, and various multi-layers depending on the application. Figure 8 shows a roll coated by flame-spraying of NiCrBSi and Figure 9 another roll coated by HVOF spraying of WC-Co, which size is underlined by the person next to it.

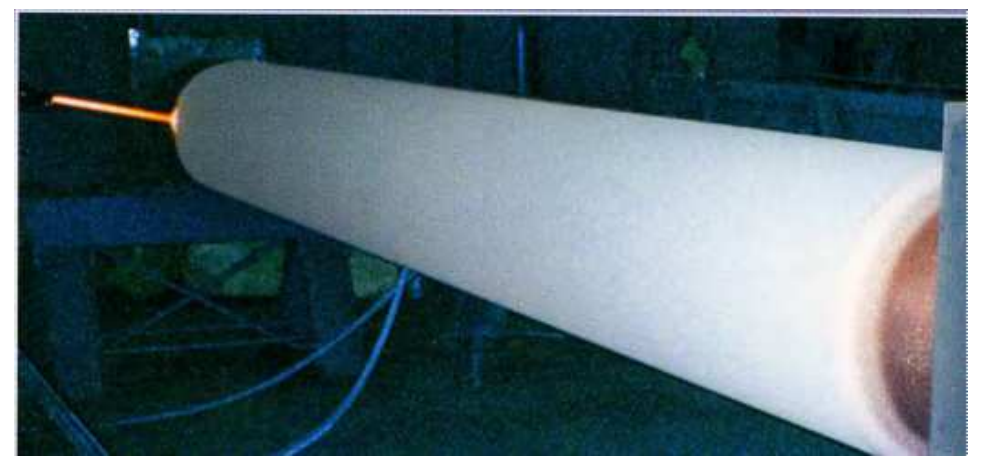

Fig. 8. Paper machine roll coated by NiCrBSi (self fluxing alloy)Vuoristo and Nylen, (2007).

When oxide coatings are used to protect such rolls, one of the problems is the expansion mismatch between the ceramic coating and the metal (for example 5-6 10-6 $\mathrm{K}^{-1}$ for iron and zirconia). Functionally graded (FG) coatings help to increase the compatibility between ceramic coatings and metallic substrates as coating properties such as coefficient of thermal expansion (CTE) and elastic modulus gradually change in order to reduce the thermal stresses within the coating Hannula et al (2009). Post-treatments, such as the deposition of coating with fluoro-polymers or the sealing of coatings to protect them against corrosive environment, are also used. Few examples are presented below:

- Press rolls are used to remove water from the sheet using mechanical forces. First they were made of granite rock and were very expensive with limited rotation velocity. Now cast iron or steel roll bodies with coatings are used. The coatings are application-specific and tailored to perform optimally under production conditions of various types of paper. Factors such as wear and corrosion resistances, and the functionality of the roll 
surface in paper manufacturing process, are key properties in these applications Vuoristo and Nylen, (2007). In most cases alumina-titania and chromia coatings are used with HVOF-deposited bond coat Davis (2004). According to the size of the coated cylinders, high power plasma torches $(250 \mathrm{~kW})$, such as Plazjet, are generally used for coating deposition.

- $\quad$ Dryer cylinders of paper machines and large Yankee drying cylinders of tissue paper machines are protected by HVOF-sprayed coatings of cermets containing various carbides. According to their weight and size, these components are commonly coated on-site and all the coating process stages (surface preparation, coating, surface finish) are carried out in the paper factory Vuoristo and Nylen, (2007). Figure 9 represents HVOF WC-Co coating of a paper machine after finishing.

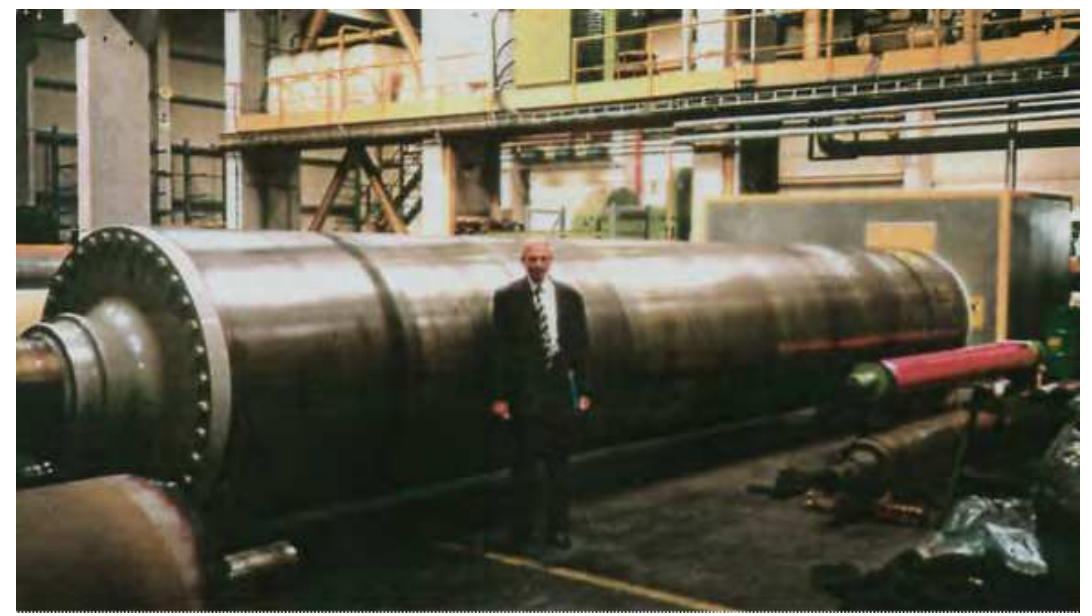

Fig. 9. Paper roll HVOF coated with WC-Co (87-13 wt \%) Ducos (2006).

The coatings are generally top-coated with a fluoro-polymer layer to improve the release properties of the roll surfaces Vuoristo and Nylen, (2007). Steels with high molybdenum contents (better corrosion resistance and thermal conductivity) HVOF sprayed are also used Davis (2004).

Carbon Fiber-Reinforced Plastics rolls (CFRP roll) exhibiting excellent characteristics including lightweight, high-stiffness, and low-flexure have been increasingly employed in manufacturing industrial fields. Compared to conventional metal rolls, CFRP rolls are lighter and stiffer, and exhibit lower inertia moment Nagai et al (2009). Unfortunately carbide-cermet coatings failed because of their poor thermal shock resistance on CFPR rolls. Ni-base composite porous coating including ceramics particles developed by Nagai et al (2009) showed high thermal-shock resistance. Five coated rolls were installed in the actual papermaking line. They achieved successful results with $10 \%$ improvement of the line speed, whereby outstanding performance and maintenance-free has been confirmed even after 4 years of use. Yoshiya et al (2009) have developed a 5.4-m length thermal sprayed carbon roller, installed in a paper slitter/winder, that is moving stably at ultrahigh speed, $2300 \mathrm{~m}^{\mathrm{min}} \mathrm{m}^{-1}$, with no abrasive wear. The roller has a three-layer structure: a tungsten carbide cermet layer on grooved metal sleeve, which covers the CFRP substrate roller shell. 
The thermal spay process is the finishing process as no grinding is performed after cermet coating deposition.

\subsubsection{Printing industry}

According to Döering et al (2008) who made an extensive review of thermal spray processes in printing: "the printing processes need all an ink transferring unit, a print form and an impression cylinder". The requirements for an appropriate coating in terms of the function but also the requirements for the grinding and finishing steps after the coating process are rather high, as illustrated with few examples:

- The ink transporting systems in offset printing machines consist of several different rollers, providing a homogenous film of ink for the print form. For example the ductorroller elevates the ink from the ink box to the ink conditioning system. Its surface roughness $\mathrm{Rz}$ must be better than $2 \mu \mathrm{m}$ and tolerances must be better than 2/1000 mm in concentricity. Such conditions are achieved with chromia rich coating consisting of a metal bond coat (Ni, NiCr, NiAl) and a ceramic topcoat Döering et al (2008).

- In contrast to common offset inking units, the anilox unit consists of a laser-engraved roller, taking the ink from a chamber doctor blade system Döering et al (2008). The gravure procedure is performed after finishing the roller surface. Producing pure chromia coatings implies using carefully adapted plasma spray conditions and adapted powders, for more details see the paper of Pawlowski (1996).

- Many other rolls are used in printing machines Döering et al (2008) with plasma sprayed oxide coatings (chromia, alumina-titania (3 or $13 \mathrm{wt} \%)$ ). Recently Lima and Marple (2005) have proposed to replace the alumina-titania coatings that are conventionally plasma sprayed, by HVOF-sprayed nanostructure titania coating exhibiting a very dense (nearly pore free) and uniform isotropic microstructure with an excellent wear and corrosion resistance.

- Other rolls such as blanket cylinders are coated with Hastelloy C by either APS or HVOF and at last draw rolls are coated with nickel-chromium Davis (2004).

\subsection{High temperature coatings}

Hot corrosion degradation of metals and alloys is a serious problem for many high temperature applications in aggressive environment, such as boilers, internal combustion engines, gas turbines, fluidized bed combustion, industrial waste incinerator. The depletion of high-grade fuels and use of residual fuel or oil in energy generation systems contribute to corrosive degradation. Residual fuel oil contains sodium, vanadium, and sulfur as impurities. The latter react together to form low melting point compounds, known as ash, which settle on the surface of materials and induce accelerated oxidation (hot corrosion). Corrosion occurs when these molten compounds dissolve the protective oxide layers that naturally form on materials during boiler/gas turbine operation. In the following a few examples will be presented according to industries. However it must be underlined that the same coating can be used for example against corrosion in gas turbines, internal combustion engines, and boilers and industrial waste incinerators. Solutions were found in the use of sophisticated materials, that are resistant to oxidation and corrosion at high and low temperatures and exhibit high-strength, e.g. nickel- base superalloy Inconel 625. However coatings of these materials on cheaper metals would be cheaper than bulk super-alloy. 
Tuominen et al (2000) have shown that HVOF-sprayed Inconel 625 coatings presented mechanical and corrosion properties typically inferior to wrought materials due to the chemical and structural inhomogeneity of the thermal-sprayed coating material. Laser remelting, with high-power continuous wave Nd:YAG laser equipped with large beam optics, resulted in the homogenization of the sprayed structure and strongly improved the performance of the laser-remelted coatings in adhesion, wet corrosion, and hightemperature oxidation testing.

\subsubsection{Metal processing industries}

Many parts in metal working industries are submitted to severe wear and corrosion and thermal sprayed coatings can help to maintain the parts. The main parts that can be protected by thermal spraying are Davis (2004): components of electric arc furnace (EAF) and basic oxygen furnace (BOF), molds, casting dies, casting salvage, molten metal containment and delivery, steel mill rolls working in both wet and dry mill environment: entrance and exit rolls of steel processing line, rolls for galvanized and aluminized steel sheets.

Components of furnaces: A wide variety of components associated with electric arc furnace (EAF) and Basic Oxygen Furnace (BOF) are subjected to severe attack from heat, particulate and acidic gases. Water-cooled components, in the off-gas duct systems such as pans, roofs, boxes and panels, are subjected to high-velocity combustion gases that contain a number of corrosives chemicals that condense and attack the heat transfer surfaces. Coatings used are those developed for high-temperature wear and corrosion resistance (see the articles of Wang and Verstak (1999), Higuera Hidalgo et al (2001), Sidhu et al (2005),(2006), Kaushal et al (2011)).

Molds: In continuous casting the cast shell in the lower half of the mold abrades and wears the bottom of the mold. The diffusion of the copper substrate from the mold into the surface of the cast product leads to a quality defect called "star cracking". Chrome- and nickel-based coatings protect copper molds from wear, and also enhance caster product quality by greatly reducing cast product contamination and star cracking problems. Thermal barrier coatings are also used to control the heat flow and retard rapid chilling Sanz (2001), Davis (2004). For very corrosive melts, pure yttria is used instead of zirconia partially stabilized with yttria. They are deposited onto a metal bond coat. Multi-layer coatings can also be used to achieve a good compliance between the expansion coefficients of mold and topcoat. Sanz (2001) has studied different coatings to protect the mold wall. Gibbons and Hansell (2006) have shown that $\mathrm{Cr}_{2} \mathrm{C}_{3}-25(\mathrm{Ni}-20 \mathrm{Cr})$ and $\mathrm{WC}-10 \mathrm{Co}-4 \mathrm{Cr}$ coatings deposited using JP5000 HVOF hardware, offer properties that could enable low-cost, low-volume production aluminum injection mold tooling to be upgraded to higher volume production tooling.

Casting salvage is also achieved by filling the voids of porosity or wear zones, after grinding, with plasma or wire-arc sprayed coatings that are then re-machined Davis (2004).

Die casting: Hot dipping rolls: $\mathrm{MoB} / \mathrm{CoCr}$, a novel cermet material for thermal spraying, with high durability in molten alloys has been developed for aluminum die-casting parts, and for hot continuous dipping rolls in $\mathrm{Zn}$ and $\mathrm{Al}-\mathrm{Zn}$ plating lines, Mizuno and Kitamura (2007). The tests revealed that the $\mathrm{MoB} / \mathrm{CoCr}$ coating has a high durability without dissolution in the molten Al-45wt.\% Zn alloy. Using undercoat is effective to reduce the effect of large difference in thermal expansion between the $\mathrm{MoB} / \mathrm{CoCr}$ topcoat and 
substrate of stainless steel of AISI 316L, widely used for the hot continuous dipping Mizuno and Kitamura (2007). MoB-based cermet powders (MoB/NiCr and $\mathrm{MoB} / \mathrm{CoCr}$ ) were deposited on SKD61 (AISI H-13) substrates used as a preferred die (mold) material Khan et al (2011). The durability of these coatings on cylindrical specimens against soldering has also been investigated by immersing them in molten aluminum alloy (ADC-12) for $25 \mathrm{~h}$ at 670 ${ }^{\circ} \mathrm{C}$. The comparison with the durability of $\mathrm{NiCr}$ and $\mathrm{CoMoCr}$ coatings under the same condition showed that both types of MoB-based cermet coatings have high soldering resistance as negligible intermetallic formation occurred during the immersion test.

Weiss et al (1994) have used arc-sprayed steel-faced tooling to create matched die sets for injection molding applications.

Entrance and exit rolls of steel processing line: when tungsten carbide coatings are used on bridle and accumulator rolls in entrance and exit ends of a steel processing line damage of the roll surface is eliminated, proper grip provided and slippage prevented. The surface coating is properly textured to provide the required characteristics or profile on the strip surface. Multi-component white cast iron is a new alloy that belongs to system Fe-C-Cr-WMo-V; it seems promising for rolls when deposited by HVOF spraying Maranho et al (2009).

Galvanized and aluminized steel sheets: They require very high surface quality, particularly in exposed panels. In continuous galvanizing and aluminizing, the steel strip is dipped in the molten bath through a series of rolls, which control the speed and tension of the strip and guide the steel strip through the molten metal bath. The rolls operating in the molten $\mathrm{Zn}-\mathrm{Al}$ alloy are subjected to severe corrosive environment and require frequent change and repair. Seonga et al (2001) have shown that WC-Co coatings are not very good with molten Zn-Al. By coating the sink rolls and stabilizer rolls with molybdenum boride, tungsten carbide and other materials, the rolls remain smoother and produce an improved strip surface.

Sheet metal forming dies: Conventionally mold and dies are manufactured by machining from bulk metallic materials. Tooling by using arc spray process to spray metal directly onto a 3D master pattern is an alternative method to manufacture mold and dies for plastic injection molding and other applications, Seong (2009).

\subsubsection{Chemical industry}

Coatings in chemical industry are used for pressure and storage vessels with Hastelloy B or C, Inconel 600. In heat-affected zones, the solutions used in gas turbines (see section 4.4.6) are often employed. In some chemical reactors dealing with strong acids in combination with organic solvents, glass lining are used and can be repaired by APS sprayed tantalum coatings, bonding well to the glass with an overlay of chromium oxide Davis (2004). For oil, gas, and petrochemical industries the following components are protected with thermal sprayed coatings : mud drill rotors, pump impellers, plunger, turbine, rotor shaft of centrifugal compressor/pump, pump shafts, boiler tube, mixing screw, mandrels, actuator shafts and housings, housings and valves, valve gates and seats, ball valve with large diameter, progressive cavity mud motor rotors, rock drill bits, riser tensioner rods, impeller /blade drilling and production risers, sub-sea piping, wellhead connectors, fasteners, compressor rods, mechanical seals, pump impellers, tank linings, external pipe coatings, structural steel coating.... 


\subsubsection{Electrical utilities}

Coatings against corrosion and wear (C-W) are used in fluidized-bed combustor (FBC) and conventional coal-fired boilers:

Fluidized-bed combustor boilers: the problem is linked to the finely divided mixtures of coal and limestone particles eroding and corroding steam pipes and boiler walls, as well as the high sulfur content of coals or low grade combustibles resulting in corrosion at hightemperature. Different coatings are used:

- $\mathrm{Cr}_{2} \mathrm{O}_{3}\left(20\right.$ wt \%)- $\mathrm{Al}_{2} \mathrm{O}_{3}$ on NiCrAlY bond coat that protects against corrosion through the porous ceramic coating, Davis (2004). The addition of approximately $20 \mathrm{wt} \%$ chromia results in the formation of one solid solution of $(\mathrm{Al}-\mathrm{Cr})_{2} \mathrm{O}_{3}$ in the a-phase modification; working temperatures can reach $1000{ }^{\circ} \mathrm{C}$ and the transformation of $\mathrm{Y}$ phase starts around $900^{\circ} \mathrm{C}$.

- HVOF sprayed $\mathrm{Cr}_{3} \mathrm{C}_{2}-\mathrm{NiCr}$ coatings with high compactness and fine grain size, Wang (1996). The wear resistance is due to the particles of hard carbide homogeneously distributed within the coating, the ductile matrix being corrosive-resistant.

Coal-fired boilers: Plasma-sprayed stellite- 6 coating has been found to be effective in increasing the erosion-corrosion resistance of boiler steels in the coal-fired boiler environment. A less porous structure obtained after laser re-melting was found to be effective for increasing erosion-corrosion resistance, Sidhu and Prakash (2006). Inconel systems or high chromium alloys or chromium-nickel alloys coatings, presenting a good resistance to sulfur have also been used, sprayed with plasma, wire-arc or HVOF Davis (2004). Notomi and Sakakibara (2009) have proposed low cost plasma-sprayed coatings with high hardness, developed by adding carbon and hardening elements to high chromium cast iron (C-Si-Mn-Cr-Mo-V-other-Fe) used for wear resistant material. Nitrogen gas atomization was applied to manufacture the powder in order to prevent the oxidation of particles. These coatings showed the same or better erosion resistance than $\mathrm{Cr}_{3} \mathrm{C}_{2}-\mathrm{NiCr}$ cermet coating, and had higher reliability for long period operation and higher practicality.

\subsubsection{Ceramic and glass manufacturing}

For the production of a variety of glasses, platinum is currently used to withstand the abrasive action of molten glass, because of its high melting point, strength and resistance to corrosion. Rhodium is often alloyed with platinum to increase the strength of the alloy and extend the life of the equipment. According to the prices of these metals, instead of using them as plates or sheets, they are often plasma-sprayed in inert atmosphere chambers where over-sprayed powder can be collected. A ceramic coating that is re-applied regularly according to its wear Davis (2004) can protect these precious metal coatings.

The electric glass melting for homogenizing, feeding and shaping was developed with molybdenum electrode materials. Since stirrers, mixing paddles, and some mold surfaces are plasma coated with molybdenum and its alloys Davis (2004).

Mold glass material must have sufficient strength, hardness and accuracy (no deforming process) at high temperature and pressure. Also, its oxidation resistance must be good, its thermal expansion low and its thermal conductivity high. Therefore, the mold material choice depends critically on the transition temperature of the glass material. For low 
temperature-transition-glasses, steel molds with a nickel alloy coating can be used, e.g. selffluxing alloy $\mathrm{NiCrBSi}$ flame-sprayed and refused. For higher transition temperatures $\mathrm{NiCr}-$ $\mathrm{Cr}_{2} \mathrm{C}_{3}$ or $\mathrm{TiC}$ cermets are used.

\subsubsection{Aerospace}

As illustrated in Figure 10, many parts (hundreds of components) are covered by thermal sprayed coatings in aircraft engine. If, at the beginning coatings were APS and VPS sprayed, HVOF spraying has been rapidly adapted to needs and twin-arc spray process is now explored. Coatings are used against fretting wear, for friction, reduction, for clearance control and for high temperature protection (thermal barrier coatings, TBC). They are also used as seals and to replace hard chromium in landing gear Davis (2004).

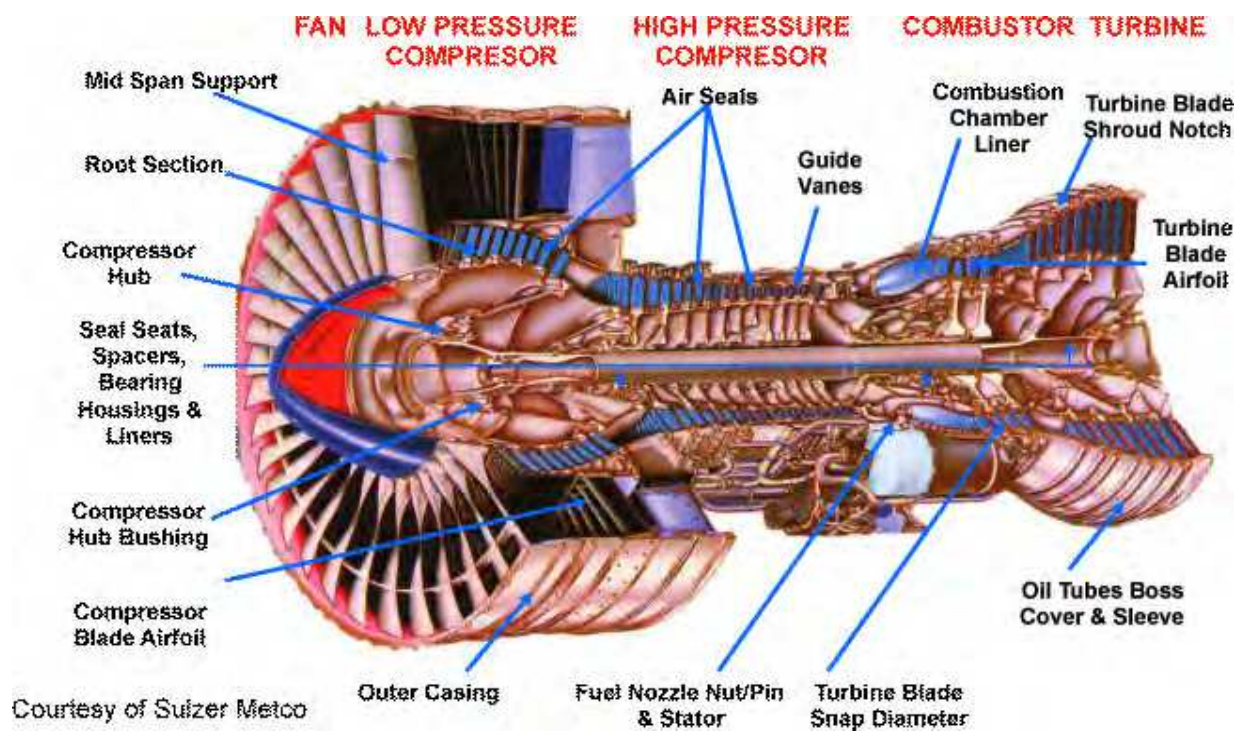

Fig. 10. Plasma-sprayed coatings on aircraft turbine engine parts (Courtesy of Sultzer-Metco)

TBCs were first successfully tested in the turbine section of a research gas turbine engine in the mid-1970s. By the early 1980s they had entered revenue service on the vane platforms of aircraft gas turbine engines, Miller (1997), Bose and de Masi-Marsin (1997), and today they are flying in revenue service on vane and blade surfaces, Golosnoy et al (2009). Thermal insulation benefits provided by TBCs and the resulting impact on component creep and thermo-mechanical fatigue life have made them enablers of high-thrust gas turbine engines. As underlined by Pratt and Whiteny, of particular importance are the TBCs elaborated by EB-PVD (Electron beam physical vapor deposition) that present an excellent compliance upon thermal cycles and can improve blade life by a factor of three Bose and de Masi-Marsin (1997). The aging of TBC's topcoat depends strongly upon the spray conditions and powder morphologies used to spray or deposit it, conditions acting on its sintering Golosnoy et al (2009), Cipitria et al (2009), Markocsan et al (2009). The second problem is the oxidation of bond coat with the formation of Thermally Grown Oxide (TGO) Feuerstein et al (2008) as well as the bond coat corrosion with oxides such as CMAS (calcium-magnesium-alumino- 
silicate) Li et al (2010), Vassen, Giessen et al (2009) or vanadium oxide Chen et al (2009). Feuerstein et al (2008) have shown that the most advanced thermal barrier coating (TBC) systems for the hot section components (combustors, blades and vanes) of aircraft engines and power generation systems, consist of EBPVD-applied (Electron Beam Physical Vapor Deposition) yttria-stabilized zirconia coating and platinum modified diffusion aluminide bond coating. Thermally-sprayed ceramic and MCrAlY bond coatings, however, are still used extensively for combustors and power generation blades and vanes. Feuerstein et al (2008) have reviewed and compared the state of the art of processes for the deposition of TBC systems: shrouded plasma and HVOF for MCrAlY bond coat, plasma for low density YSZ and dense vertically cracked Zircoat, platinum aluminide diffusion coatings, EBPVD TBC. They outlined and compared the key features and cost of coatings actually used in industry. Vassen, Stuke et al (2009), Vassen et al (2010) have presented the last developments using advanced processing (e.g. methods making it possible to obtain highly segmented TBCs) and the important recent directions of development for TBC systems, including improved processing routes and advanced TBC materials. Many works are devoted to the bond coat resistance, Pint et al (2010) and deal with the ways to improve it, Toscano et al (2006), Schulz et al (2008), by bond coat treatment or choice of the spray process Richer et al (2010). For the TBC topcoat, promising innovative technologies such as TF-LPPS (Thin FilmLow Pressure Plasma Spraying) Hospach et al (2011) or plasma spraying of liquid feedstock (solution or suspension) or of nanometer sized agglomerated particles will probably play an increasing role in future applications Lima and Marple (2007), Fauchais et al (2011).

In the lower and higher-temperature sections of engines, carbide cermets are the common materials used against fretting. Below $540{ }^{\circ} \mathrm{C}$ tungsten carbides in cobalt matrices (6 to $12 \mathrm{wt}$ $\%$ ) with chromium addition (4 to $12 \mathrm{wt} \%$ ) are used and at higher temperatures chromium carbides in NiCr matrices are used Davis (2004). HVOF spraying is often used to limit the decomposition of carbides.

In compressors, gas turbines and turbochargers, dimensional changes take place between the rotor and stator components because of thermal and mechanical effects during operation. These dimensional changes affect sealing, so, clearance control systems are used. They consist of a sacrificial element and a cutting component. Thermal spray coatings, called abradables, and honeycomb seals form effective sacrificial systems. Abradable coatings are machined in-situ and consist of a soft metal with polymer particles in cold sections and Nigraphite of MCrAlY with polyester or BN particles in hot areas Davis (2004), Ma and Matthews (2009), Johnston (2011). Additives provide the necessary friability, as well as aid in dry lubrication. Other thermal sprayed coatings can also be used on the 'cutting' side of the clearance control system, and also when the dynamic member of the system is too soft to cut without a coating.

\subsubsection{Land-based turbine}

Compared to aero engines, land-based turbines work under different conditions: the external environment might range from cold $\left(-40^{\circ} \mathrm{C}\right)$ to high temperature $\left(55-60{ }^{\circ} \mathrm{C}\right)$ and corrosive and erosive contaminants due to the environment and fuel are present. Coatings are applied onto bearing journals, bearing seals, sub shaft journal, labyrinth seals, blades, tip seals, inlet and exhausts and housing Davis (2004). A detailed description of the different 
land-based turbines can be found in the paper of Lebedev and Kostennikov (2008). Pomeroy (2005) gives a detailed description of coatings for gas turbine materials and long-term stability issues. Due to the demand to increase turbine inlet temperatures and thus cycle efficiencies, ceramic insulating coatings can be applied to decrease the temperature of the hottest parts of the turbine components by up to $170{ }^{\circ} \mathrm{C}$. Turbines are exposed to excessive amounts of moisture and chlorides. In addition, two types of hot corrosion and oxidation occur:

- $\quad$ Type II hot corrosion occurring at temperatures in the range $500-800{ }^{\circ} \mathrm{C}$ and involving the formation of base metal (nickel or cobalt) sulphates which require a certain partial pressure of sulphur trioxide for their stabilization,

- Type I hot corrosion, observed in the range $750-950{ }^{\circ} \mathrm{C}$, involving the transport of sulphur from a sulphatic deposit (generally $\mathrm{Na}_{2} \mathrm{SO}_{4}$ ) across a preformed oxide into the metallic material with the formation of the most stable sulphides. Once stable sulphide formers (e.g. Cr) are fully reacted with the sulphur moving across the scale, then base metal sulphides can form with catastrophic consequences as they are molten at the temperatures at which Type I hot corrosion occurs.

At last oxidation starts at temperatures over $1000^{\circ} \mathrm{C}$.

Sprayed materials with good corrosion and oxidation resistance are nickel- and/or cobaltbased alloyed coatings Davis (2004), e.g. NiCrMo (Hastelloy or Nistelle), CoCrSiMo (Triballoy), and MCrAlYs, that are either plasma or HVOF sprayed. Oxidation- and corrosion-resistant coatings are applied on air-inlets, combustor liners, injectors, turbine tip shoes, nozzles and exhausts. MCrAlY coatings are used on blades and vanes as bond coats and for corrosion-oxidation protection.

For thermal barrier coatings, mainly $\mathrm{ZrO}_{2}-\mathrm{Y}_{2} \mathrm{O}_{3}$ (6 to $8 \mathrm{wt} \%$ ), ceria or dysprosia stabilized zirconia are used Curry et al (2011) and also ceria and yttria stabilized zirconia or, for certain applications, calcium titanate Davis (2004). It is worth underlying that for abradable and seals in the low-temperature areas, where moisture is important porous aluminum-base coatings containing polyester, polyimide or $\mathrm{BN}$ as well as nickel-graphite coatings are used. For higher temperatures (over $450^{\circ} \mathrm{C}$ ) abradables are made of MCrAlY with BN or polyester Davis (2004), Wilson et al (2008). Ceramic abradables have also been introduced but the expansion mismatch with the metal substrate must be accounted for with the cooling of the super alloy.

\subsubsection{Other industries}

As previously described, thermal spray coatings provide superior wear (abrasive, erosive, fretting...) resistance and corrosion protection with coatings having low porosity, high hardness, good toughness for cermets, and great flexibility of composition. Thus they are also used in:

Nuclear industry: the use of cobalt-based alloys (stellites or cermets matrix) is limited, thus coatings against wear and corrosion rely on nickel alloy based coatings ( $\mathrm{NiCr}-\mathrm{WC}$ or $\mathrm{NiCr}$ $\mathrm{Cr}_{3} \mathrm{C}_{2}$ ). Cermets with hafnium-carbide that present a large neutron cross-section have been developed. However, thermal sprayed coatings are essentially used in pumps, turbines, heat exchangers, vanes... For example Figure 11 presents a spherical vane that was HVOF coated. 
In numerous applications developed at CEA-DEN, French Atomic Agency, Atomic Energy Department, particularly those encountered in the processing of nuclear wastes, metallic components are subjected to extreme environments in service, in terms, for example, of ageing at moderated temperature (several months at about $300{ }^{\circ} \mathrm{C}$ ) coupled to thermal shocks (numerous cycles up to $850^{\circ} \mathrm{C}$ for a few seconds and a few ones up to $1500{ }^{\circ} \mathrm{C}$ ) under a reactive environment made of a complex mixture of acid vapors in the presence of an electric field of a few hundred volts and a radioactive activity Berard et al (2008). The authors have tested alumina plasma-sprayed coatings manufactured with feedstock of different particle size distributions, graded alumina-titania coatings, and phosphate-sealed alumina coatings to improve the properties of metallic substrates operating in such extreme environments. The effects of particle size distribution, phosphate sealant, and graded titania additions on the dielectric strength of the as-sprayed, thermally cycled and thermally aged coatings were investigated. Thermal ageing test was realized in furnace at $350{ }^{\circ} \mathrm{C}$ for $400 \mathrm{~h}$ and thermal shocks tests resulted from cycling the coating between 850 and $150{ }^{\circ} \mathrm{C}$ using oxyacetylene flame and compressed air-cooling. Aluminum phosphate impregnation appeared to be an efficient post-treatment to fill the connected porosity of coatings. Alumina as-sprayed coatings manufactured with $+22-45 \mu \mathrm{m}$ and $+5-20 \mu \mathrm{m}$ particle size distributions exhibited good dielectric strengths after thermal solicitations compared to coatings manufactured with bigger size distributions or to graded titania coatings.

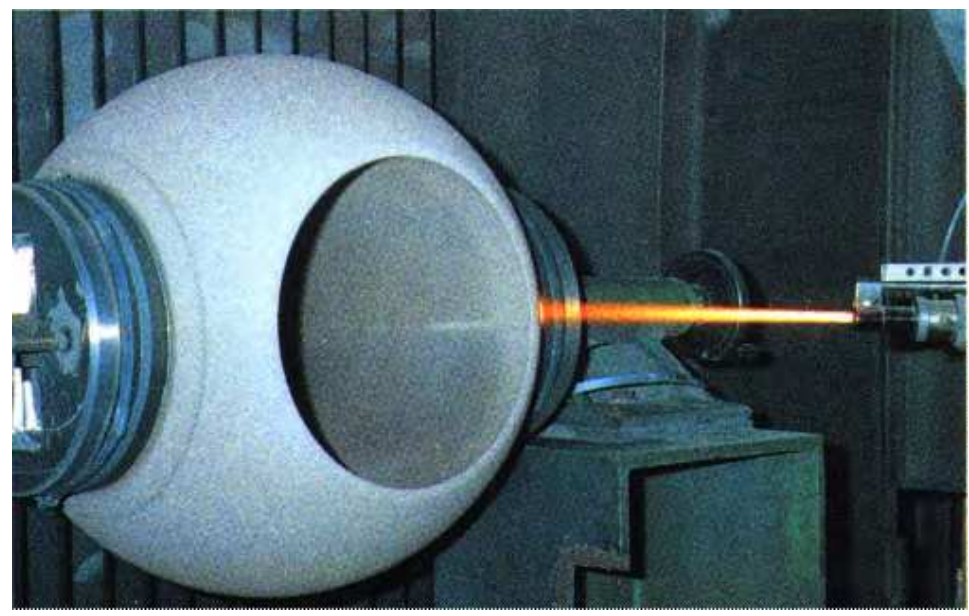

Fig. 11. HVOF coated spherical vane for nuclear industry Ducos (2006).

- Cement industry: Again the main role of sprayed coatings is wear and corrosion protection of mechanical seal, sleeve, burner tip, boiler tube, thermo-well, kiln support roll, pinion shaft, coating for cement preheat tower, impeller blade, calender roll, cone crusher and hydraulic rams with acid resistant coatings...

- Drawing Machine: guide roller and ceramic disc, rod breakdown drawing machine, fine drawing machine and other accessories

- Waste treatment: The oxidation of steel tubes causes an important problem in Municipal Solid Waste Incinerator (MSWI) plants due to burned wastes containing high concentrations of chemically active compounds of alkali, sulfur, phosphorus and 
chlorine. Ni-based HVOF coatings are a promising alternative to the MSWI conventional protection against chlorine environments, Wang (1996), Guilemany et al (2007). To protect substrates from hot corrosion Shidu et al (2007) studied WC$\mathrm{NiCrFeSiB}$ coatings HVOF sprayed to provide nickel and iron-based super alloys with the necessary resistance against oxidation and hot corrosion under the given environmental conditions at $800{ }^{\circ} \mathrm{C}$. The oxides of active elements of the coatings, formed in the surface scale as well as at the boundaries of nickel and tungsten rich splats, contributed for the oxidation and hot corrosion resistance of WC-NiCrFeSiB coatings, as these oxides act as barriers for the diffusion/penetration of the corrosive species through the coatings. According to the study of Lee et al (2007) there are 88 waste-to-energy (WTE) plants in the U.S. and over 600 worldwide. In total, they combust close to 143 million metric tons of municipal solid wastes (MSW) and generate about 45 billion kW.h of electricity and an equal amount of thermal energy for district heating and industrial use. The presence of various impurities, especially $\mathrm{HCl}$ and chloride salts, in the combustion gases results in much higher corrosion rates of boiler tubes and has led to the development of special alloys and also metal protection techniques, including HVOF-sprayed coatings. The application of corrosion resistant materials by means of the HVOF or plasma spray processes has shown to be the best combination of erosion-corrosion resistance among all other thermal spray processes Uusitalo et al (2002). In practical applications, NiCrSiB alloy HVOF coatings and Inconel 625 plasma sprayed coatings have been used successfully on water-wall tubes while $\mathrm{TiO}_{2}-\mathrm{Al}_{2} \mathrm{O}_{3} / 625$ cement $\mathrm{HVOF}$ coatings applied on super-heater tubes show long-term durability of more than 3 years Fukuda et al (2000). Shidu, Prakash and Agrawal (2006) have characterized the $\mathrm{HVOF}$ sprayed $\mathrm{Cr}_{3} \mathrm{C}_{2}-\mathrm{NiCr}$ coating on Ni-based superalloys and evaluated their performance in an aggressive environment of $\mathrm{Na}_{2} \mathrm{SO}_{4}-60 \% \mathrm{~V}_{2} \mathrm{O}_{5}$ salt mixture at $900{ }^{\circ} \mathrm{C}$ under cyclic conditions. The coating was resistant to hot corrosion in the given molten salt environment at $900{ }^{\circ} \mathrm{C}$, which has been attributed to the formation of oxides of nickel and chromium, and spinels of nickel-chromium.

Coal-Gasification: Shidu et al (2007) have studied the resistance to corrosion (exposure to molten salt at $900{ }^{\circ} \mathrm{C}$ under cyclic conditions) of $\mathrm{Cr}_{3} \mathrm{C}_{2}-\mathrm{NiCr}, \mathrm{NiCr}$, WC-Co and Stellite-6 alloy coatings sprayed on ASTM SA213-T11 steel using the HVOF process. Liquid petroleum gas was used as the fuel gas. Hot corrosion studies were conducted on the uncoated as well as HVOF sprayed specimens All these overlay coatings showed a better resistance to hot corrosion as compared to that of uncoated steel. $\mathrm{NiCr}$ coating was found to be most protective followed by the $\mathrm{Cr}_{3} \mathrm{C}_{2}-\mathrm{NiCr}$ coating. WC-Co coating was least effective to protect the substrate steel. It was concluded that the formation of $\mathrm{Cr}_{2} \mathrm{O}_{3}, \mathrm{NiO}, \mathrm{NiCr}_{2} \mathrm{O}_{4}$, and $\mathrm{CoO}$ in coatings might contribute to better hot-corrosion resistance. The uncoated steel suffered corrosion in the form of intense spalling and peeling of the scale, which may be due to the formation of un-protective $\mathrm{Fe}_{2} \mathrm{O}_{3}$ oxide scale.

\subsection{Coatings against corrosive wear}

Corrosive wear occurs when the effects of corrosion and wear are combined, resulting in a more rapid degradation of the material's surface. A surface that is corroded or oxidized may be mechanically weakened and more likely to wear at an increased rate. Furthermore, corrosion products including oxide particles that are dislodged from the material's surface can subsequently act as abrasive particles. Stress corrosion failure results from the combined 
effects of stress and corrosion. At high temperatures reactions with oxygen, carbon, nitrogen, sulfur or flux result in the formation of oxidized, carburized, nitrided, sulfidized, or slag layer on the surface. Temperature and time are the key factors controlling the rate and severity of high temperature corrosive attack Chattopadhyay (2001).

A few examples are presented below. An important concern in the oil and gas production industry is the behavior of materials in an aggressive environment with the presence of suspended sand particles, which contribute to corrosion, erosion and overall wear of the surface. Al-Fadhli et al (2006) have HVOF-sprayed Inconel-625 onto stainless steel components used in oil/gas industry. Coatings were applied on three different metallic surfaces: (a) plain stainless steel (SS), (b) spot-welded stainless steel (SW-SS), and (c) a composite surface of stainless steel and carbon steel welded together (C-SS-CS). These coated surfaces were tested in a jet impingement rig under two fluid conditions: (i) free from added solids, (ii) containing $1 \%$ silica sand. The coating was found to be highly sensitive to the presence of sand particles in the impinging fluid. As the period of coating exposure to the flow of slurry fluid increased, weight loss increased significantly. This increment was dependent on the type of substrate material.

WC-Co HVOF-sprayed coatings present poor resistance to corrosive wear: the tungsten carbide in HVOF coatings dissolves as well as the cobalt-chromium matrix, leading to cobalt in solution. WC and Co go through an oxidation process before dissolution, the oxidation of $\mathrm{WC}$ to $\mathrm{WO}_{3}$ makes the $\mathrm{pH}$ drop, accelerating the dissolution of cobalt and corrosion of hard phase leading to its removal. So, there are serious implications when coatings are used in corrosive-erosive environments Souza and Neuville (2006). These authors have tested WC-CoCr HVOF-sprayed coatings. They have shown that the corrosion of these coatings is very complex and corrosion rate increases with temperature. However, chromium forms an oxide layer, which protects from dissolution and retards the corrosion. Toma et al (2001) found similar results, concluding that due to its low erosion-corrosion rate the HVOF sprayed $\mathrm{Cr}_{3} \mathrm{C}_{2}-\mathrm{NiCr}$ coating can be considered to be an excellent replacement for the thermal sprayed $\mathrm{Cr}_{2} \mathrm{O}_{3}$ coatings. Espallargas et al (2008) found that both WC-Ni and $\mathrm{Cr}_{3} \mathrm{C}_{2}-$ $\mathrm{NiCr}$ coatings are promising alternatives to hard chromium from the point of view of erosion-corrosion resistance.

Plasma-sprayed aluminum oxide and chromium oxide coatings are widely used to improve the resistance of metallic components against various types of wear and corrosion. However their corrosion resistance depends strongly on their porosity, especially open pores. Leivo et al (1997) used aluminum phosphates to seal the structures of $\mathrm{Al}_{2} \mathrm{O}_{3}$ and $\mathrm{Cr}_{2} \mathrm{O}_{3}$ coatings. The abrasive wear resistance of sealed coatings did not decrease after immersion tests of 30 days in liquids of $\mathrm{pH} 0$ to 10, except for the $\mathrm{Al}_{2} \mathrm{O}_{3}$ coating, which corroded in $\mathrm{pH} 0$ and $\mathrm{pH} 14$ solutions. No corrosion was found with aluminum phosphates in very acidic solutions. Aluminum phosphate is a good candidate to seal oxide coatings that are exposed in corrosive environments, excluding high basic environments of approximately $\mathrm{pH} 14$.

In diesel engines, sulfur contain in the fuel induces corrosive attack possibility. Uusitalo et al (2005) have tested the newly developed ferrous powder (Fe-C-Ni-Cr-Cu-V-B alloy) plasma sprayed with the Rota-Plasma ${ }^{\circledR}$ of Sultzer-Metco on Al-13Si cylinder wall. It presented excellent corrosion and wear resistances, compared with currently used bulk casting materials such as Fe - C - Si - B alloy and Fe - C - Si - Mo - B alloy for cylinder liners. 
Basak et al (2006) have tested the corrosion and corrosion-wear behavior of thermal sprayed nanostructured $\mathrm{FeCu}$ /WC-Co coating in Hank's solution and compared the results with that of stainless steel AISI 304 and nanostructured WC-Co coatings. The multiphase structure of the $\mathrm{FeCu} / \mathrm{WC}-\mathrm{Co}$ coating induces a complex corrosion behavior. Under corrosion-wear conditions, the nanostructured $\mathrm{FeCu} / \mathrm{WC}-\mathrm{Co}$ coating exhibited a depassivation/repassivation behavior comparable to that of stainless steel AISI 304 and nanostructured WC-Co coatings.

Generally speaking, thermal sprayed coatings behave better when their density is improved. For example Liu et al (2007) have investigated the effects of laser surface treatment on the corrosion and wear performance of Inconel 625, and Inconel 625-based WC HVOF-sprayed metal matrix composite coatings. Significant improvement of corrosion and wear resistance were achieved after laser treatment as a result of the elimination of discrete splat-structure, micro-crevice and porosity, and also the reduction of micro-galvanic driving force between the WC and the metal matrix. In addition, the formation of faceted dendritic structure of the WC phase was considered to be beneficial for the wear performance.

\section{Conclusions}

Thermal sprayed thick (from 50 to $3000 \mu \mathrm{m}$ ) coatings, including cold spray coatings are more and more used in industry for the following reasons: (i) They provide specific properties onto substrates which properties are very different from those of the sprayed coating; (ii) They can be applied with rather low or no heat input to substrates (allowing for example spraying ceramics onto polymer substrates); (iii) Virtually any material that melts without decomposing or vaporizing can be sprayed including cermets or very complex metal or ceramic mixtures, allowing tailoring coatings to the wished service property; (iv) Sprayed coatings can be strip off and the worn or damaged coatings recoated without changing part properties and dimensions; (v) Some spray processes can be moved on site, allowing spraying rapidly big parts, which displacement would otherwise be rather long and expensive.

The main thermal-sprayed coatings drawbacks are the following: (i) They are a line-of-sight technology, e.g. making it impossible to coat small and deep cavities; (ii) Most coatings have lamellar structures with contacts between layered splats that represent between 15 and $60 \%$ of the splat surfaces depending on spray conditions; (iii) They have pores, cracks... that can be connected, depending on the spray process and spray conditions, and that must be sealed for certain applications.

Most bulk materials used in corrosion conditions can be sprayed, however splat boundaries and cracks (for ceramics coatings) often dominate the corrosion properties of coatings. Sacrificial coatings (cathodic behavior relatively to ions, for example $\mathrm{Zn}$ or Al on steel) are extensively used for the protection of large steel structures such as bridges, pipelines, oil tanks, towers, radio and television masts, overhead walkways and large manufacturing facilities, as well as for structures exposed to moist atmospheres and seawater such as ships, offshore platforms and seaports. Their porosity does not affect the anodic material protection, except when the whole cathodic coating structure is completely corroded. Painting as sealing or densification by shot peening are often used to extend their lifetime. No-sacrificial coatings, against corrosion or corrosive wear are extensively used in many 
industries: aerospace, land-based turbines, automotive, ceramic and glass manufacturing, printing industry, pulp and paper, metal processing, chemical, nuclear, cement, waste treatment... However, in almost all cases these coatings must be retreated to get rid of their porosity. This is achieved by using self-fluxing alloys that are fused after spraying, heat treating or annealing, laser glazing, austempering, sealing with organic, inorganic, metals... peening densification, diffusion... Such post-treatments increase the cost of coatings. However, in many cases the cost of retreated coatings is lower than the use of bulk materials and this is especially the case for the repair of parts.

\section{References}

Al-Fadhli H.Y., J. Stokes, M.S.J. Hashmi, B.S. Yilbas, (2006) The erosion-corrosion behavior of high velocity oxy-fuel (HVOF) thermally sprayed inconel-625 coatings on different metallic surfaces, Surface \& Coatings Technology 200, 5782-5788

Barletta M., G. Bolelli, B. Bonferroni, and L. Lusvarghi, (2010) Wear and Corrosion Behavior of HVOF-Sprayed WC-CoCr Coatings on Al Alloys, Journal of Thermal Spray Technology 19(1-2) 358-367

Basak A.K., P. Matteazzi, M. Vardavoulias, J.-P. Celis, (2006) Corrosion-wear behavior of thermal sprayed nanostructured FeCu/WC-Co coatings, Wear 261, 1042-1050

Berard G., P. Brun, J. Lacombe, G. Montavon, A. Denoirjean, and G. Antou, (2008)®Influence of a Sealing Treatmenton the Behavior of Plasma-Sprayed Alumina Coatings Operatingin Extreme Environments, Journal of Thermal Spray Technology17(3)410-419

Bose S. and J. de Masi-Marcin, (1997) Thermal Barrier Coating Experience in Gas Turbine Engines at Pratt \& Whitney, Journal of Thermal Spray Technology 6(1) 99-104

Candel A.and R. Gadow, (2006) Optimized multiaxis robot kinematic for HVOF spray coatings on complex shaped substrates, Surface \& Coatings Technology 201, 20652071

Chattopadhyay R., (2001) Surface Wear: Analysis, Treatment, and Prevention (pub.) ASM Int. Materials Park, OH, USA, 307 p.

Chen Z., J. Mabon, J.-G. Wen, R. Trice, (2009) Degradation of plasma-sprayed yttriastabilized zirconia coatings via ingress of vanadium oxide, Journal of the European Ceramic Society 291647-1656

Chen H., H. Zhao, J. Qu and H. Shao, (1999) Erosion-Corrosion of Thermal-Sprayed Nylon Coatings, Wear 233-235 431-435

Chun-long Y., A. Yun-qi, S. Ya-tan, (2009) Three Years Corrosion Tests of Nanocomposite Epoxy Sealer for Metalized Coatings on the East China Sea, in Thermal Spray 2009: Proc. of the International Thermal Spray Conference (eds.) B.R. Marple, M.M. Hyland, Y.-C. Lau, C.-J. Li, R.S. Lima, G. Montavon (pub. ASM Int, Materials Park, OH, USA 1090-1093

Cipitria A., I.O. Golosnoy, T.W. Clyne, (2009) A sintering model for plasma-sprayed zirconia TBCs. Part I: Free-standing coatings, Acta Materialia 57 980-992

Ctibor P., R. Lechnerová, V. Beneš, (2006) Quantitative analysis of pores of two types in a plasma-sprayed coating, Materials Characterization 56 297-304

Curry N., N. Markocsan, X.-H. Li, A. Tricoire, and M. Dorfman, (2011) Next Generation Thermal Barrier Coatings for the Gas Turbine Industry, Journal of Thermal Spray Technology 20(1-2) 108-115 
Davis J. R. (ed.) (2004) Handbook of Thermal Spray Technology (pub.) ASM Int. Materials Park OH, USA.

Döring J.-E., F. Hoebener and G. Langer, (2008) Review of applications of thermal spraying in the printing industry in respect to OEMs, in Thermal Spray Conference: Crossing the Border (ed.) E. Lugsheider (pub.) DVS, Düsseldorf, Germany e-Proc.

Ducos M. (2006) Costs evaluation in thermal spray, Continuing education course, ALIDERTE, Limoges, France

Espallargas N., J. Berget, J.M. Guilemany, A.V. Benedetti, P.H. Suegama, (2008) $\mathrm{Cr}_{3} \mathrm{C}_{2}-\mathrm{NiCr}$ and WC-Ni thermal spray coatings as alternatives to hard chromium for erosioncorrosion resistance, Surface \& Coatings Technology 202 1405-1417

Evdokimenko Yu. I., V. M. Kisel', V. Kh. Kadyrov, A. A. Korol', and O. I. Get'man, (2001) High-Velocity Flame Spraying of Powder Aluminum Protective Coatings, Powder Metallurgy and Metal Ceramics 40(3-4) 121-126

Fauchais P., G Montavon, R S Lima and B R Marple, (2011) Engineering a new class of thermal spray nano-based microstructures from agglomerated nanostructured particles, suspensions and solutions: an invited review, J. Phys. D: Appl. Phys. 44 093001

Fauchais P., J. Heberlein and M. Boulos, (2012) Thermal spraying, (pub.) Elsevier Amsterdam, NL, to be published

Fedrizzi L., L. Valentinelli, S. Rossi, S. Segna, (2007) Tribocorrosion behaviour of HVOF cermet coatings, Corrosion Science 49 2781-2799

Feuerstein A., J. Knapp, T. Taylor, A. Ashary, A. Bolcavage, and N. Hitchman, (2008) Technical and Economical Aspects of Current Thermal Barrier Coating Systems for Gas Turbine Engines by Thermal Spray and EBPVD: A Review, Journal of Thermal Spray Technology 17(2) 199-213

Fukuda Y., K. Kawahara, and T. Hosoda, (2000) Application of High Velocity Flame Sprayings for Superheater Tubes in Waste Incinerators, Corrosion 2000, 00264.100264.14

Gärtner F.,T. Stoltenhoff, T. Schmidt, and H. Kreye, (2006) The Cold Spray Process and Its Potential for Industrial Applications, Journal of Thermal Spray Technology,15(2) 223-232

Gawne D.T., B.J. Griffiths, and G. Dong, (1995) Splat Morphology and Adhesion of Thermally Sprayed Coatings, in Thermal Spraying: Current Status and Future Trends Kobe, Japan (1995) (Ed.) A. Ohmori,), (Pub.) High Temperature Society of Japan,pp 779-784

Golosnoy I.O., A. Cipitria, and T.W. Clyne, (2009) Heat Transfer Through Plasma-Sprayed Thermal Barrier Coatings in Gas Turbines: A Review of Recent Work, Journal of Thermal Spray Technology 18(5-6) 809-821

Guilemany J.M., M. Torrell, J.R. Miguel, (2007) Properties of HVOF Coating of Ni Based Alloy for MSWI Boilers Protection, in Thermal Spray 2007: Global Coating Solutions (eds.) B.R. Marple, M.M. Hyland, Y.-C. Lau, C.-J. Li, R.S. Lima, and G. Montavon(pub.) ASM Int., Materials Park, OH, USA, (2007) e-proc.

Hannula S.-P., E. Turunen, J. Koskinen, O. Söderberg, (2009) Processing of hybrid materials for components with improved life-time, Current Applied Physics 9, S160-S166 
Gibbons G. J. and R. G. Hansell, (2006) Down-Selection and Optimization of ThermalSprayed Coatings for Aluminum Mould Tool Protection and Upgrade, Journal of Thermal Spray Technology 15(3) 340-347

Harsha S., D.K. Dwivedi , A. Agrawal, (2007) Influence of WC addition in Co-Cr-W-Ni-C flame sprayed coatings on microstructure, microhardness and wear behavior, Surface \& Coatings Technology $2015766-5775$

Henne R. H. and C. Schitter, (1995) Plasma spraying of high performance thermoplastics, in Thermal Spray Science and Technology (eds.) C. C. Berndt and S. Sampath (pub.) ASM Int., Materials Park, OH, USA, 527-532

Hermanek, F.J., (2001) Thermal Spray Terminology and Company Origins (pub.) ASM International, Materials Park, Ohio, USA.

Higuera Hidalgo V., F.J. Belzunce Varela, A. Carriles Menéndez, S. Poveda Martinez, (2001)A comparative study of high-temperature erosion wear of plasma-sprayed $\mathrm{NiCrBSiFe}$ and WC-NiCrBSiFe coatings under simulated coal-fired boiler conditions, Tribology International 34, 161-169

Holcomb G.R., S.D. Cramer, S.J. Bullard, B.S. Covino, Jr, W.K. Collins, R.D. Govier, G.E. McGill, (1997) Characterization of thermal-sprayed titanium anodes for cathodic protection, in Thermal Spray: A United Forum for Scientific and Technological Advances (ed.) C.C. Berndt (pub.) ASM Int., OH, USA 141-150

Hospach A., G. Mauer, R. Vaßen, and D. Stöver, (2011) Columnar-Structured Thermal Barrier Coatings (TBCs) by Thin Film Low-Pressure Plasma Spraying (LPPS-TF), Journal of Thermal Spray Technology 20 (1-2) 116-120

Ishikawa Y., J. Kawakita, S. Osawa, T. Itsukaichi, Y. Sakamoto, M. Takaya, and S. Kuroda, (2005) Evaluation of Corrosion and Wear Resistance of Hard Cermet Coatings Sprayed by Using an Improved HVOF Process, Journal of Thermal Spray Technology 14(3) 384-390

Johnston R.E., (2011) Mechanical characterisation of AlSi-hBN, NiCrAl-Bentonite, and NiCrAl-Bentonite-hBN freestanding abradable coatings, Surface \& Coatings Technology 205, 3268-3273

Kaushal G., H. Singh, and S. Prakash, (2010) High-Temperature Erosion-Corrosion Performance of High-Velocity Oxy-Fuel Sprayed Ni-20Cr Coating in Actual Boiler Environment, Metallurgical and Materials Transactions A, 42(7) 1836-1846

Khan F. F., G. Bae, K. Kang, H. Na, J. Kim, T. Jeong, and C. Lee, (2011) Evaluation of DieSoldering and Erosion Resistance of High Velocity Oxy-Fuel Sprayed MoB-Based Cermet Coatings, Journal of Thermal Spray Technology 20(5) 1022-1034

Knuuttila J., P. Sorsa1, T. Mäntylä, J. Knuuttila and P. Sorsa, (1999) Sealing of thermal spray coatings by impregnation, Journal of Thermal Spray Technology 8(2) 249-25

Lebedev A. S. and S. V. Kostennikov, (2008) Trends in Increasing Gas-Turbine Units Efficiency, Thermal Engineering 55(6) 461-468

Lee S.-H., N. J. Themelis and M. J. Castaldi, (2007) High-Temperature Corrosion in Waste-toEnergy Boilers, Journal of Thermal Spray Technology16(1) 104-110

Leivo E., T. Wilenius, T. Kinos, P. Vuoristo, T. Mäntylä, (2004) Properties of thermally sprayed fluoropolymer PVDF, ECTFE, PFA and FEP coatings, Progress in Organic Coatings 49 69-73 
Leivo E.M., M.S. Vippola, P.P.A.Sorsa, P.M.\& Vuoristo, and T.A.Mäntylä, (1997) Wear and Corrosion Properties of Plasma Sprayed $\mathrm{Al}_{2} \mathrm{O}_{3}$ and $\mathrm{Cr}_{2} \mathrm{O}_{3}$ Coatings Sealed by Aluminum Phosphates, Journal of Thermal Spray Technology 6(2) 205-210

Lenling W.J., M.F. Smith and J.A. Henfling, (1991) Beneficial effects of austempering posttreatment on tungsten carbide based wear coatings, in Thermal Spray Research and Applications (ed.) T.F. Bernecki (pub.) ASM Int. Materials Park, OH, USA 227-232

Li L., N. Hitchman, and J. Knapp, (2010) Failure of Thermal Barrier Coatings Subjected to CMAS Attack, Journal of Thermal Spray Technology 19(1-2) 148-155

Lima R.S. and B.R. Marple, (2007) Thermal Spray Coatings Engineered from Nanostructured Ceramic Agglomerated Powders for Structural, Thermal Barrier and Biomedical Applications: A Review, Journal of Thermal Spray Technology 16(1) 40-63

Lima R.S. and B.R. Marple, (2005) Superior Performance of High-Velocity Oxyfuel-Sprayed Nanostructured TiO2 in Comparison to Air Plasma-Sprayed Conventional $\mathrm{Al}_{2} \mathrm{O}_{3}$ $13 \mathrm{TiO}_{2}$, Journal of Thermal Spray Technology 14(3) 397-404

Lin L. and K.Han, (1998) Optimization of surface properties by flame spray coating and boriding, Surface and Coatings Technology 106 100-105

Liu Z., J. Cabrero, S. Niang, Z.Y. Al-Taha, (2007) Improving corrosion and wear performance of HVOF-sprayed Inconel 625 and WC-Inconel 625 coatings by high power diode laser treatments, Surface \& Coatings Technology 201, 7149-7158

Ma X., A. Matthews, (2009) Evaluation of abradable seal coating mechanical properties, Wear 267, 1501-1510

Maranho O., D. Rodrigues, M. Boccalini, and A. Sinatora, (2009) Bond Strength of Multicomponent White Cast Iron Coatings Applied by HVOF Thermal Spray Process, Journal of Thermal Spray Technology 18(4) 708-713

Markocsan N., P. Nylén, J. Wigren, X.-H. Li, and A. Tricoire, (2009) Effect of Thermal Aging on Microstructure and Functional Properties of Zirconia-Base Thermal Barrier Coatings, Journal of Thermal Spray Technology 18(2) 201-208

Meng H., (2010) The performance of different WC-based cermet coatings in oil and gas applications-A comparison, in ITSC 2010 Thermal spray: global solutions, future applications (pub.) DVS Düsseldorf, Germany e-proc.

Miller R.A., (1997) Thermal Barrier Coatings for Aircraft Engines: History and Directions, Journal of Thermal Spray Technology 6(1) 35-42

Mizuno H. and Junya Kitamura, (2007) MoB/CoCr Cermet Coatings by HVOF Spraying against Erosion by Molten Al-Zn Alloy, Journal of Thermal Spray Technology 16(3) 404-413

Moskowitz L. N., (1993) Application of HVOF thermal spraying to solve corrosion problems in the petroleum industry-an industrial note, Journal of Thermal Spray Technology 2(1) 21-29

Murakami K.and M. Shimada, (2009) Development of Thermal Spray Coatings with Corrosion Protection and Antifouling Properties, in Thermal Spray 2009: Proceedings of the International Thermal Spray Conference (eds.) B.R. Marple, M.M. Hyland, Y.-C. Lau, C.-J. Li, R.S. Lima, G. Montavon (pub.) ASM Int. Materials Park, OH,USA 1041-1044

Nagai M., S. Shigemura, A. Yoshiya, (2009) Thermal-Sprayed CFRP Roll with Resistant to Thermal Shock and Wear - For Papermaking Machine - in Thermal Spray 2009: Proceedings of the International Thermal Spray Conference (eds.) B.R. Marple, 
M.M. Hyland, Y.-C. Lau, C.-J. Li, R.S. Lima, G. Montavon (pub.) ASM Int., Materials Park, OH,USA 607-611

Notomi A., N. Sakakibara, (2009) Recent Application of Thermal Spray to Thermal Power Plants, in Thermal Spray 2009: Proceedings of the International Thermal Spray Conference (eds.) B.R. Marple, M.M. Hyland, Y.-C. Lau, C.-J. Li, R.S. Lima, G. Montavon (pub.) ASM Int.Materials Park, OH, USA 1106-1111

Pacheo da Silva C. et al, (1991) 2nd Plasma Technik Symposium 1 363-373 (Pub.) Plasma Technik Wohlen, $\mathrm{CH}$

Pawlowski L., (1996) Technology of thermally sprayed anilox rolls: State of art, problems, and perspectives, Journal of Thermal Spray Technology, 5(3) 317-334

Petrovicova E. and L. S. Schadler, (2002) Thermal Spraying of Polymers, Int. Mater. Rev., 47(4) 169-190

Pint B.A., J.A. Haynes, Y. Zhang, (2010) Effect of superalloy substrate and bond coating on TBC lifetime Surface \& Coatings Technology 205 1236-1240

Pomeroy M.J., (2005) Coatings for gas turbine materials and long term stability issues, Materials and Design 26, 223-231

Racek O., (2010) The Effect of HVOF Particle-Substrate Interactions on Local Variations in the Coating Microstructure and the Corrosion Resistance, Journal of Thermal Spray Technology 19(5) 841-851

Richer P., M. Yandouzi, L. Beauvais, B. Jodoin, (2010) Oxidation behavior of CoNiCrAlY bond coats produced by plasma, HVOF and cold gas dynamic spraying, Surface \& Coatings Technology 204, 3962-3974

Sanz A., (2001) Tribological behavior of coatings for continuous casting of steel, Surface and Coatings Technology $146-147,55-64$

Schulz U., O. Bernardi, A. Ebach-Stahl, R. Vassen, D. Sebold, (2008) Improvement of EBPVD thermal barrier coatings by treatments of a vacuum plasma-sprayed bond coat, Surface \& Coatings Technology 203, 160-170

Scrivani A., S. Ianelli, A. Rossi, R. Groppetti, F. Casadei, G. Rizzi, (2001) A contribution to the surface analysis and characterisation of HVOF coatings for petrochemical application, Wear 250, 107-113

Seong B.-G., J.-H. Kim, J.-H. Ahn, K.-H. Baik, (2009) A Case Study of Arc-spray Tooling Process for Production of Sheet Metal Forming Dies, in Thermal Spray 2009: Proceedings of the International Thermal Spray Conference (eds.) B.R. Marple, M.M. Hyland, Y.-C. Lau, C.-J. Li, R.S. Lima, G. Montavon, (pub.) ASM Int., Materials Park, OH, USA, e-proc. 562-566

Seong B.G., S.Y. Hwanga, M.C. Kima, K.Y. Kimb, (2001) Reaction of WC-Co coating with molten zinc in a zinc pot of a continuous galvanizing line, Surface and Coatings Technology 138, 101-110

Sidhu H.S., B.S. Sidhu, and S. Prakash, (2007) Hot Corrosion Behavior of HVOF Sprayed Coatings on ASTM SA213-T11 Steel, Journal of Thermal Spray Technology16(3) 349-354

Sidhu T.S., A. Malik, S. Prakash, and R.D. Agrawal, (2007) Oxidation and Hot Corrosion Resistance of HVOF WC-NiCrFeSiB Coatingon Ni- and Fe-based Superalloys at 800 ${ }^{\circ} \mathrm{C}$, Journal of Thermal Spray Technology16(5-6) 844-849

Sidhu B. S., Prakash S., (2006) Erosion-corrosion of plasma as sprayed and laser remelted Stellite-6 coatings in a coal fired boiler, Wear 260, 1035-1044 
Sidhu H. S., Sidhu B. S., and S. Prakash, (2006) Comparative Characteristic and Erosion Behavior of NiCr Coatings Deposited by Various High-Velocity Oxyfuel Spray Processes, Journal of Materials Engineering and Performance 5(6) 699-704

Sidhu T.S., S. Prakash, and R.D. Agrawal, (2006) Characterizations and Hot Corrosion Resistance of $\mathrm{Cr} 3 \mathrm{C} 2-\mathrm{NiCr}$ Coating on Ni-Base Superalloys in an Aggressive Environment, Journal of Thermal Spray Technology 15(4) 811-816

Sidhu T. S., S. Prakash, and R. D. Agrawal, (2005) Studies on the Properties of High-Velocity Oxy-Fuel Thermal Spray Coatings for Higher Temperature Applications, Materials Science 41(6) 805-823

Souza V.A.D. and A. Neville, (2006) Mechanisms and Kinetics of WC-Co-CrHigh Velocity Oxy-Fuel Thermal Spray Coating Degradation in Corrosive Environments, Journal of Thermal Spray Technology 15(1) 106-117

Souza V.A.D., A. Neville, (2003) Linking electrochemical corrosion behavior and corrosion mechanisms of thermal spray cermet coatings ( $\mathrm{WC} / \mathrm{CrNi}$ and $\mathrm{WC} / \mathrm{CrC} / \mathrm{CoCr}$ ), Materials Science and Engineering A352 202-211

Soveja A., S. Costil, H. Liao, P. Sallamand, and C. Coddet, (2010) Remelting of Flame Spraying PEEK Coating Using Lasers, Journal of Thermal Spray Technology 19(1-2) 439-447

Toma D., W. Brandl, G. Marginean, (2001) Wear and corrosion behaviour of thermally sprayed cermet coatings, Surface and Coatings Technology 138, 149-158

Toscano J., R. Vassen, A. Gil, M. Subanovic, D. Naumenko, L. Singheiser, W.J. Quadakkers, (2006) Parameters affecting TGO growth and adherence on MCrAlY-bond coats for TBC's Surface \& Coatings Technology 201, $3906-3910$

Tuominen J., P. Vuoristo, T. Mäntylä, M. Kylmälahti, J. Vihinen, and P.H. Andersson, (2000) Improving Corrosion Properties of High-VelocityOxy-Fuel Sprayed Inconel 625 by Using a High-Power Continuous Wave Neodymium-DopedYttrium Aluminum Garnet Laser, Journal of Thermal Spray Technology 9(4) 513-519

Uozato S., K. Nakata, (2005) M. Ushio, Evaluation of ferrous powder thermal spray coatings on diesel engine cylinder bores,Surface \& Coatings Technology 2002580 - 2586

Uusitalo M.A., P.M.J. Vuoristo, and T.A. Mantyla, (2002) ElevatedTemperature ErosionCorrosion of Thermal Sprayed Coatings in Chlorine Containing Environments, Wear 252(7-8) 586-594

Vaßen R., M. O. Jarligo, T. Steinke, D. E. Mack, D. Stöver, (2010) Overview on advanced thermal barrier coatings, Surface \& Coatings Technology 205 938-942

Vaßen R., S. Giesen, and D. Stöver, (2009)Lifetime of Plasma-Sprayed Thermal Barrier Coatings: Comparison of Numerical and Experimental Results, Journal of Thermal Spray Technology 18(5-6) 835-845

Vassen R., A. Stuke, and D. Stöver, (2009) Recent Developments in the Field of Thermal Barrier Coatings, Journal of Thermal Spray Technology 18(2) 181-186

Vuoristo P.and P. Nylen, (2007) Industrial and Research Activities in Thermal Spray Technology in the Nordic Region of Europe Journal of Thermal Spray Technology 16(4) 466-471

Wang B.-Q., A. Verstak, (1999) Elevated temperature erosion of HVOF Cr3C2/TiC- NiCrMo cermet coating, Wear 233-235 342 - 351

Wang B., (1996) Erosion-corrosion of thermal sprayed coatings in FBC boilers, Wear 199 2432 
Weiss L. E., D. G. Thuel, L. Schultz and F. B. Prinz, (1994) Arc-sprayed steel-faced tooling, Journal of Thermal Spray Technology 3(3) 275-281

Wilson S., D. Sporer, and M. R. Dorfman, (2008) Technology advances in compressor and turbine abradables, in Thermal Spray Conference: Crossing Borders (ed.) E. Lugsheider (pub.) DVS, Düsseldorf, Germany (2008) e-proc

Yoshiya A., S. Shigemura, M. Nagai, M. Yamanaka, (2009) Advances of Thermal Sprayed Carbon Roller in Paper Industry, in Thermal Spray 2009: Proceedings of the International Thermal Spray Conference (eds.) B.R. Marple, M.M. Hyland, Y.-C. Lau, C.-J. Li, R.S. Lima, G. Montavon (pub.) ASM Int., Materials Park, OH,USA 601606

Zhang C., G. Zhang, V. JI, H. Liao, S. Costil, C. Coddet, (2009) Microstructure and mechanical properties of flame-sprayed PEEK coating remelted by laser process, Progress in Organic Coatings 66, 248-253

Zhang J., Z. Wang, P. Lin, W. Lu, Z. Zhou, and S. Jiang, (2011) Effect of Sealing Treatment on Corrosion Resistance of Plasma-Sprayed NiCrAl/Cr2O3-8 wt.\%TiO2 Coating, Journal of Thermal Spray Technology 20(3) 508-513

Zhang T., D.T. Gawne, Y. Bao, (1997) The influence of process parameters on the degradation of thermally sprayed polymer coatings, Surface and Coatings Technology 96 337-344

Zeng Z., N. Sakoda, T. Tajiri, S. Kuroda, (2008) Structure and corrosion behavior of 316L stainless steel coatings formed by HVAF spraying with and without sealing, Surface \& Coatings Technology 203 284-290 


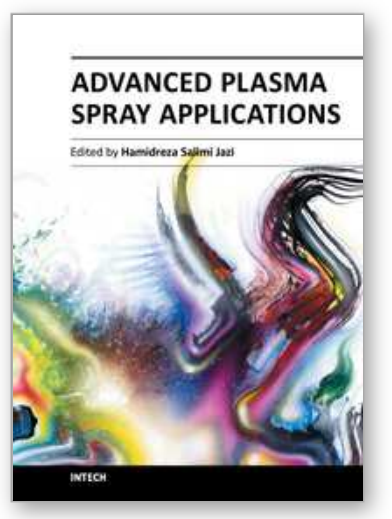

\author{
Advanced Plasma Spray Applications \\ Edited by Dr. Hamid Jazi
}

ISBN 978-953-51-0349-3

Hard cover, 250 pages

Publisher InTech

Published online 21, March, 2012

Published in print edition March, 2012

Recently, plasma spray has been received a large number of attentions for various type of applications due to the nature of the plasma plume and deposition structure. The plasma gas generated by the arc, consists of free electrons, ionized atoms, some neutral atoms, and undissociated diatomic molecules. The temperature of the core of the plasma jet may exceed up to $30,000 \mathrm{~K}$. Gas velocity in the plasma spray torch can be varied from subsonic to supersonic using converging-diverging nozzles. Heat transfer in the plasma jet is primarily the result of the recombination of the ions and re-association of atoms in diatomic gases on the powder surfaces and absorption of radiation. Taking advantages of the plasma plume atmosphere, plasma spray can be used for surface modification and treatment, especially for activation of polymer surfaces. I addition, plasma spray can be used to deposit nanostructures as well as advanced coating structures for new applications in wear and corrosion resistance. Some state-of-the-art studies of advanced applications of plasma spraying such as nanostructure coatings, surface modifications, biomaterial deposition, and anti wear and corrosion coatings are presented in this book.

\title{
How to reference
}

In order to correctly reference this scholarly work, feel free to copy and paste the following:

P. Fauchais and A. Vardelle (2012). Thermal Sprayed Coatings Used Against Corrosion and Corrosive Wear, Advanced Plasma Spray Applications, Dr. Hamid Jazi (Ed.), ISBN: 978-953-51-0349-3, InTech, Available from: http://www.intechopen.com/books/advanced-plasma-spray-applications/thermal-sprayed-coatings-usedagainst-corrosion-and-corrosive-wear

\section{INTECH}

open science | open minds

\section{InTech Europe}

University Campus STeP Ri

Slavka Krautzeka 83/A

51000 Rijeka, Croatia

Phone: +385 (51) 770447

Fax: +385 (51) 686166

www.intechopen.com

\section{InTech China}

Unit 405, Office Block, Hotel Equatorial Shanghai

No.65, Yan An Road (West), Shanghai, 200040, China 中国上海市延安西路65号上海国际贵都大饭店办公楼 405 单元

Phone: +86-21-62489820

Fax: $+86-21-62489821$ 
(C) 2012 The Author(s). Licensee IntechOpen. This is an open access article distributed under the terms of the Creative Commons Attribution 3.0 License, which permits unrestricted use, distribution, and reproduction in any medium, provided the original work is properly cited. 